NBER WORKING PAPER SERIES

\title{
A MULTIPLIER APPROACH TO UNDERSTANDING THE MACRO IMPLICATIONS OF HOUSEHOLD FINANCE
}

\author{
YiLi Chien \\ Harold Cole \\ Hanno Lustig \\ Working Paper 13555 \\ http://www.nber.org/papers/w13555 \\ NATIONAL BUREAU OF ECONOMIC RESEARCH \\ 1050 Massachusetts Avenue \\ Cambridge, MA 02138 \\ November 2007
}

We would like to thank Bernard Dumas, Francisco Gomes, Mark Hugget, Urban Jermann, Narayana Kocherlakota, Dirk Krueger, Pete Kyle, Mark Loewenstein, Joseph Ostroy, Nikolai Roussanov, Viktor Tsyrennikov, Stijn Van Nieuwerburgh and Amir Yaron for comments. Andrew Hollenhurst provided excellent research assistance. We would also like to especially thank the editor Kjetil Storesletten and two anonymous referees for their efforts to improve our paper. The views expressed herein are those of the author(s) and do not necessarily reflect the views of the National Bureau of Economic Research.

(C) 2007 by YiLi Chien, Harold Cole, and Hanno Lustig. All rights reserved. Short sections of text, not to exceed two paragraphs, may be quoted without explicit permission provided that full credit, including (C) notice, is given to the source. 
A Multiplier Approach to Understanding the Macro Implications of Household Finance

YiLi Chien, Harold Cole, and Hanno Lustig

NBER Working Paper No. 13555

November 2007, Revised January 2010

JEL No. G12

\begin{abstract}
$\underline{\text { ABSTRACT }}$
Our paper examines the impact of heterogeneous trading technologies for households on asset prices and the distribution of wealth. We distinguish between passive traders who hold fixed portfolios of stocks and bonds, and active traders who adjust their portfolios to changes in expected returns. To solve the model, we derive an optimal consumption sharing rule that does not depend on the trading technology, and we derive an aggregation result for state prices. This allows us to solve for equilibrium prices and allocations without having to search for market-clearing prices in each asset market separately. We show that the fraction of total wealth held by active traders, not the fraction held by all participants, is critical for asset prices, because only these traders respond to variation in state prices and hence absorb the residual aggregate risk created by non-participants. We calibrate the heterogeneity in trading technologies to match the equity premium and the risk-free rate. The calibrated model reproduces the skewness and kurtosis of the wealth distribution in the data. In contrast to existing models with heterogeneous agents, our model matches the high volatility of returns and the low volatility of the risk-free rate.

YiLi Chien

403 West State Street

Krannert School of Management

Purdue University

West Lafayette

IN 47907

yilichien@gmail.com

Harold Cole

Economics Department

University of Pennsylvania

3718 Locust Walk

160 McNeil Building

Philadelphia, PA 19104

and NBER

colehl@sas.upenn.edu

Hanno Lustig

UCLA Anderson School of Management

110 Westwood Plaza, Suite C413

Los Angeles, CA 90095-1481

and NBER

hlustig@anderson.ucla.edu
\end{abstract}




\section{Introduction}

Incomplete market models in which all households can only trade a highly limited menu of tradeable assets were initially embraced to explain the strong correlation in the data between household consumption and income. However, the actual menu of assets that household can trade is very rich. At the same time, there is a growing body of empirical evidence that different households behave as if they had access to different menus of tradeable assets. 1 A majority of households does not invest directly in equity, in spite of the sizeable historical equity premium, but even among those who participate in equity markets, sophisticated investors invest a larger share of their wealth in equity and realize higher returns, while less sophisticated investors take a more cautious approach. As a result, sophisticated investors load up on aggregate consumption risk. The consumption of the $10 \%$ wealthiest households is five times more exposed to aggregate consumption growth than that of the average US household (Parker and Vissing-Jorgensen (2009)).

Heterogeneity in preferences cannot explain these differences. In a complete markets environment, when agents have constant relative risk aversion (CRRA) preferences, the most risk averse end up being the poorest households in equilibrium, only because they are the least willing to substitute intertemporally, not because of the risk preferences per se (Dumas (1989)). However, in an incomplete markets environment, the least risk averse tend to accumulate less wealth because their precautionary motive to save is not as strong, and hence they will be most exposed to both aggregate consumption and idiosyncratic risk, while the wealthiest households would end up holding less equity and be less exposed to aggregate and idiosyncratic consumption growth risk. In the data, the consumption of the wealthy is more exposed to aggregate but less to idiosyncratic risk.

These empirical findings lead us to introduce heterogeneous trading technologies in an otherwise standard incomplete markets model. To solve this model, we develop a new method that does not rely on a price adjustment algorithm to clear each asset market separately. We introduce heterogeneity in trading technologies into an endowment economy with a large number of agents who are subject to both aggregate and idiosyncratic shocks, and who have CRRA preferences with coefficient $\alpha$. Our model distinguishes between passive traders, who trade fixed-weighted portfolios of bonds and equities, and active traders, who optimally re-adjust their portfolio holdings over time. We capture the differences in trading technologies by imposing different measurability restrictions on the household's time-zero trading problem. These restrictions govern how net wealth is allowed to vary across different states of the world. We use the multipliers on these constraints to derive a consumption sharing rule for households and an analytical expression for the stochastic discount factor. Importantly, the household's consumption sharing rule does not depend on the trading technology, only the dynamics of the multipliers do. The equilibrium stochastic discount factor only depends on aggregate consumption growth and a weighted average of these multipliers -the

\footnotetext{
${ }^{1}$ Campbell (2006) refers to the body of literature that documents this heterogeneity as "household finance".
} 
$-1 / \alpha$-th moment. We refer to this simply as the aggregate multiplier.

In our approach, this household multiplier is a new state variable that replaces wealth. We characterize its dynamics by means of a simple updating rule that depends on the trading technology of the household. The individual's multiplier updating rule and the implied updating rule for the aggregate multipliers completely characterize equilibrium allocations and prices. In continuoustime finance, Cuoco and He (2001) and Basak and Cuoco (1998) used stochastic weighting schemes to characterize allocations and prices. Our approach differs because it provides a tractable and computationally efficient algorithm for computing equilibria in environments with a large number of agents subject to idiosyncratic risk as well as aggregate risk, and heterogeneity in trading opportunities. The use of cumulative multipliers in solving macro-economic equilibrium models was pioneered by Kehoe and Perri (2002), building on earlier work by Marcet and Marimon (1999). Our use of measurability constraints to capture portfolio restrictions is similar to that in Aiyagari, Marcet, Sargent, and Seppala (2002) and Lustig, Sleet, and Yeltekin (2007), who consider an optimal taxation problem, while the aggregation result extends that in Chien and Lustig (2009) and Lustig and Nieuwerburgh (2005) to an incomplete markets environment.

Our paper is closely related to work by Krusell and Smith (1997) and (1998). Krusell and Smith (1998) consider a production economy with a large number of agents in which individual labor supply is subject to exogenous idiosyncratic shocks, while the aggregate production function is subject to aggregate productivity shocks. Households in this economy only trade claims to the physical capital stock. In this model with a single asset, KS only need to solve a forecasting problem for the return on capital. Similarly, we solve a forecasting problem for the growth rate of this aggregate multiplier. However, as soon as KS add an additional asset ( e.g. a risk-free bond in Krusell and Smith (1997)), KS need to solve for the market-clearing pricing function for this asset 2 Applying this KS method in our model would require searching for a new pricing function for each additional aggregate state in each iteration, not knowing the mapping from the wealth distribution to state prices. Our aggregation result implies that we only need to forecast a single moment of the multiplier distribution, regardless of the number and the nature of the different trading technologies. We can directly compute the pricing kernel as a function of this moment. Hence, there is no need to search for the vector of state prices that clears the various asset markets. Finally, solving for the multiplier updating rule turns out to be simpler and faster than solving the household's Bellman equation or consumption Euler equation.

We apply our method in a calibrated version of the model. To capture some of the richness of trading behavior in the data, we distinguish between passive traders who hold no stocks, the non-participants, and buy-and-hold passive traders who can only trade a fixed-weighted portfolio of stocks and bonds. The heterogeneity in trading technologies is calibrated to match the equity

\footnotetext{
${ }^{2}$ Storesletten, Telmer, and Yaron (2007) implement this procedure in an OLG model with trading in capital and risk-free bonds.
} 
risk premium and the risk-free rate for a risk aversion coefficient of five, but, as an out-of-sample check, we show that the model also matches the relation between wealth and equity holdings in the data. However, the welfare costs of operating an inferior trading technology in our calibrated model are large.

The interaction between a small segment of active traders and a larger segment of passive traders improves the model's match with asset prices in the data along two dimensions: the first and the second moments of risk premia. Due to this interaction, equilibrium state prices are highly volatile and counter-cyclical, which delivers a larger average equity premium, but the conditional expectation of state prices - and hence the risk-free rate- is not. Instead, the equilibrium state prices are highly volatile across aggregate states. The non-participants create residual aggregate risk that ends up being absorbed only by the active traders, not by the buy-and-hold traders. The non-participants create residual aggregate risk, because they consume "too much" in low aggregate consumption growth states (recessions) and "too little" in high aggregate consumption growth states (expansions). On the other hand, the active traders concentrate their consumption in "cheap" aggregate states (states with low state prices for aggregate consumption). Hence, to clear the goods market, the equilibrium state prices have to be much higher in recessions to induce a small segment of active traders to consume less, and much lower in expansions to induce them to consume more. This mechanism is similar to the one explored by Guvenen (2009), but it relies on heterogeneity in trading technologies instead of preferences.

Second, the model endogenously generates counter-cyclical variation in risk premia, even when the aggregate consumption growth shocks are i.i.d. The share of total wealth owned by the active traders declines in low aggregate consumption growth states, because they take highly leveraged equity positions. As a result, the conditional volatility of state prices increases after each recession since a larger adjustment in state prices is needed to induce the smaller mass of active traders to clear the goods markets. As we increase the equity share in the passive trader portfolios, the second channel actually strengthens, and the volatility of risk premia increases, even though the first channel weakens, and average risk premia decline.

Our quantitative results contribute to a growing literature on the asset pricing impact of limited stock market participation, starting with Saito (1996), Basak and Cuoco (1998) and VissingJorgensen (2002), and more recently, by Guvenen (2009) and Gomes and Michaelides (2008). Guvenen (2009) argues that limited participation goes a long way towards explaining the equity premium in a model with a bond-only investor and a stockholder who have heterogeneous willingness to substitute consumption intertemporally. We consider a model without preference heterogeneity but with idiosyncratic risk and with heterogeneity in trading technologies among market participants 3 Overall, the consensus in the literature is that stockholders hold too much

\footnotetext{
${ }^{3}$ Gomes and Michaelides (2008) also consider a model with bond-and stockholders, but they add idiosyncratic risk.
} 
wealth in the data to fully explain the size of risk premia only by means of the limited participation mechanism. Our paper strengthens the limited participation explanation by showing that it is really the fraction of wealth held by active investors that matters, not the fraction of wealth held by all participants. In our calibrated model, more than half of the increase in the equity premium relative to the complete markets case is due to the heterogeneity in trading technologies in our model, rather than limited participation. At the same time, our model matches the asset share distribution in the data closely, while the limited participation benchmark cannot match the concentration of equity holdings in the data. More importantly, the heterogeneity in trading technologies more than doubles volatility of the market price of risk, relative to the limited participation benchmark, while the risk-free rate remains stable, and this volatility amplification does not disappear as we increase the equity holdings of passive investors. In contrast, the preference heterogeneity explored by Guvenen (2009) generates significant excess risk-free rate volatility 4

In our model, the consumption of passive traders is more exposed to idiosyncratic risk, because they fail to accumulate enough wealth to self-insure, while the consumption of active traders is more exposed to aggregate risk. This heterogeneity in the responsiveness of consumption to aggregate shocks in the model is consistent with recent evidence by Malloy, Moskowitz, and VissingJorgensen (2007) and Parker and Vissing-Jorgensen (2009), who find that wealthier stockholders have consumption that is much more exposed to aggregate shocks. The active traders in our model realize much higher returns, as documented by Calvet, Campbell, and Sodini (2007), and they adopt a sophisticated market timing strategy that exploits the time variation in the risk premium to do so. In the calibrated model, they accumulate on average three times more wealth than the average household in our model, because of their superior trading technology. This mechanism allows our model to match the skewness and kurtosis of the wealth distribution in the data, but it falls short of matching the left tail of the wealth distribution. Since these active traders are wealthy on average and since they have a high fraction of equities in their portfolio, the calibrated model delivers a closer match between wealth and equity shares in the data.

This paper is organized as follows. Section 2 describes the environment, the preferences and trading technologies for all households. Section 3 characterizes the equilibrium allocations and prices using cumulative multipliers that record all the binding measurability and solvency constraints. Section 4 describes a computational algorithm. In section 5 we study a calibrated version of our economy, section [6 does a number of sensitivity experiments: (i) we increase the participation rate to $50 \%$, which reduces the equity premium by 80 basis points, and we compare the current asset share and wealth distribution in the data to the the model's, (ii) we compare our model's predictions to that of a model with only limited participation, without heterogeneity in trading technologies, (iii) we change the composition of the passive trader segment to show that

\footnotetext{
${ }^{4}$ In addition, the aggregate consumption growth implied by his production model is twice as volatile as consumption growth in U.S. data.
} 
only the average equity holdings of passive traders matters for the asset pricing results, and (iv) we change the calibration of aggregate and idiosyncratic shocks. All the proofs are in the appendix. A separate appendix with auxiliary results is available from the authors' web sites. We have also made the matlab code available on-line.

\section{Model}

In this section we describe the environment, and we describe the household problem for each of the different asset trading technologies. We also define an equilibrium for this economy.

\section{$2.1 \quad$ Environment}

This is an endowment economy with a unit measure of households who are subject to both aggregate and idiosyncratic income shocks. Households are ex ante identical, except for the access to trading technologies. Ex post, the households differ in terms of their idiosyncratic income shock realizations. All of the households face the same stochastic process for these shocks, and all households start with the same present value of tradeable wealth.

In the model time is discrete, infinite, and indexed by $t=0,1,2, \ldots$ The first period, $t=0$, is a planning period in which financial contracting takes place. We use $z_{t} \in Z$ to denote the aggregate shock in period $t$ and $\eta_{t} \in N$ to denote the idiosyncratic shock in period $t$. $z^{t}$ denotes the history of aggregate shocks, and, similarly, $\eta^{t}$, denotes the history of idiosyncratic shocks for a household. The idiosyncratic events $\eta$ are i.i.d. across households. We use $\pi\left(z^{t}, \eta^{t}\right)$ to denote the unconditional probability of state $\left(z^{t}, \eta^{t}\right)$ being realized. The events are first-order Markov, and we assume that the transition probabilities can be decomposed as follows: $\pi\left(z^{t+1}, \eta^{t+1} \mid z^{t}, \eta^{t}\right)=$ $\phi\left(z_{t+1} \mid z_{t}\right) \pi\left(\eta_{t+1} \mid z_{t+1}, \eta_{t}\right)$. Since we can appeal to a law of large number, $\pi\left(z^{t}, \eta^{t}\right) / \pi\left(z^{t}\right)$ also denotes the fraction of agents in state $z^{t}$ that have drawn a history $\eta^{t}$. We use $\pi\left(\eta^{t} \mid z^{t}\right)$ to denote that fraction. We introduce some additional notation: $z^{t+1} \succ z^{t}$ or $y^{t+1} \succ y^{t}$ means that the left hand side node is a successor node to the right hand side node. We denote by $\left\{z^{\tau} \succ z^{t}\right\}$ the set of successor aggregate histories for $z^{t}$ including those many periods in the future; ditto for $\left\{\eta^{\tau} \succ \eta^{t}\right\}$. When we use $\succeq$, we include the current nodes $z^{t}$ or $\eta^{t}$ in the summation.

We use $\left[\eta^{t-1}, \widetilde{\eta}_{t}\right]$ to refer to a particular history of idiosyncratic events $\eta_{0}, \eta_{1}, \ldots, \eta_{t-1}, \widetilde{\eta}_{t}$, where we change only the last event. Similarly, we use $\left[z^{t-1}, \widetilde{z}_{t}\right]$ to refer to a particular history of aggregate events $z_{0}, z_{1}, \ldots, z_{t-1}, \widetilde{z}_{t}$. This notation will prove to be useful when we explain the measurability constraints.

There is a single final good in each period, and the amount of it is given by $Y\left(z^{t}\right)$, which evolves according to $Y\left(z^{t}\right)=\exp \left\{z_{t}\right\} Y\left(z^{t-1}\right)$, with $Y\left(z^{1}\right)=\exp \left\{z_{1}\right\}$. This endowment good comes in two forms. The first form is diversifiable income, which is not subject to the idiosyncratic shock, and is 
given by $(1-\gamma) Y\left(z^{t}\right)$. The other form is non-diversifiable income which is subject to idiosyncratic risk and is given by $\gamma Y\left(z^{t}\right) \eta_{t}$; hence $\gamma$ is the share of income that is non-diversifiable.

All households are infinitely lived and rank stochastic consumption streams $\left\{c\left(z^{t}, \eta^{t}\right)\right\}$ according to the following criterion

$$
U(c)=\sum_{t \geq 1}^{\infty} \sum_{z^{t}, \eta^{t}} \beta^{t} \pi\left(z^{t}, \eta^{t}\right) \frac{c\left(z^{t}, \eta^{t}\right)^{1-\alpha}}{1-\alpha},
$$

where $\alpha>0$ denotes the coefficient of relative risk aversion, and $c\left(z^{t}, \eta^{t}\right)$ denotes the household's consumption in state $\left(z^{t}, \eta^{t}\right)$.

\subsection{Asset Trading Technologies and Assets Traded}

All households are endowed with a claim to their per capita share of both diversifiable and nondiversifiable income. Households cannot directly trade their claim to non-diversifiable income.

Households trade assets in securities markets and they trade the final good in spot markets that re-open in every period. All of the households have access to only one of two asset trading technologies. We assume households cannot switch between technologies. The active traders can trade a complete menu of claims whose payoffs are contingent on the aggregate state $z^{t}$, as well as stocks and bonds. The other households are passive traders who can only trade a fixed-weighted portfolio of bonds and stocks.

In our model, equity is a leveraged claim to diversifiable income, following Abel (1999). Let $\psi$ denote the leverage parameter, let $b_{t}\left(z^{t}\right)$ denote the supply of one-period risk-free bonds, and let $R_{t}^{f}$ denote the risk-free rate. We can decompose the aggregate payout that flows from the diversifiable income claim $(1-\gamma) Y\left(z^{t}\right)$ into a dividend component $d_{t}\left(z^{t}\right)$ from equity and a bond component $R_{t}^{f}\left(z^{t-1}\right) b\left(z^{t-1}\right)-b\left(z^{t}\right)$. The bond supply adjusts in each node $z^{t}$ to ensure that the bond/equity ratio equals $\psi: b\left(z^{t}\right)=\psi\left[\omega\left(z^{t}\right)-b\left(z^{t}\right)\right]$ for all $z^{t}$, where $\omega\left(z^{t}\right)$ denotes the price of a claim to diversifiable income.

\subsection{Measurability Constraints}

To model these trading technologies, we make use of measurability constraints, a different one for each trading technology. The rest of the household constraints are standard.

We use $q\left[\left(z^{t+1}, \eta^{t+1}\right),\left(z^{t}, \eta^{t}\right)\right]$ to denote the price of a unit claim to the final good in state $\left(z^{t+1}, \eta^{t+1}\right)$ acquired in state $\left(z^{t}, \eta^{t}\right)$. The absence of arbitrage implies that there exist aggregate

state prices $q\left(z_{t+1}, z^{t}\right)$ such that $q\left[\left(z^{t+1}, \eta^{t+1}\right),\left(z^{t}, \eta^{t}\right)\right]=\pi\left(\eta^{t+1} \mid z^{t+1}, \eta^{t}\right) q\left(z_{t+1}, z^{t}\right)$, where $q\left(z_{t+1}, z^{t}\right)$ denotes the price of a unit of the final good in aggregate state $z^{t+1}$ given that we are in aggregate history $z^{t}$.

We let each household trade a complete set of contingent bonds subject to the appropriate 
measurability restrictions. Stocks and non-contingent bonds are redundant assets. For the sake of tractability, we exclude these redundant securities altogether in this section. This exclusion of redundant assets is without loss of generality, as we show in section $\mathrm{D}$ of the separate appendix 5 Given an equilibrium in the sequence economy with trade in redundant assets, there exists an equivalent equilibrium in the sequence economy in which agents trade only state-contingent bonds subject to the measurability constraints, and vice versa.

The budget constraint for this trader in state $\left(z^{t}, \eta^{t}\right)$ is:

$$
\gamma Y\left(z^{t}\right) \eta_{t}+a_{t-1}\left(z^{t}, \eta^{t}\right)-c\left(z^{t}, \eta^{t}\right) \geq \sum_{z^{t+1} \succ z^{t}} q\left(z_{t+1}, z^{t}\right) \sum_{\eta^{t+1} \succ \eta^{t}} a_{t}\left(z^{t+1}, \eta^{t+1}\right) \pi\left(\eta^{t+1} \mid z^{t+1}, \eta^{t}\right)
$$

where $a_{t-1}\left(z^{t}, \eta^{t}\right)$ denotes the number of unit claims to the final good purchased at $t-1$ for state $\left(z^{t}, \eta^{t}\right)$. The period 0 spot budget constraint is given by

$$
a_{-1}\left(z_{0}\right) \geq \sum_{z_{1}} q\left(z_{1}, z^{0}\right) \sum_{\eta_{1}} a_{0}\left(z^{1}, \eta^{1}\right) \pi\left(\eta^{1} \mid z^{1}, \eta^{0}\right)
$$

where $z^{0}$ and $\eta^{0}$ are degenerate states representing the initial position in the planning state at time 0 before any of the shocks have been realized and where $q\left(z_{1}, z^{0}\right)$ denotes the price in this stage of a claim to consumption in period 1 .

In addition to their spot budget constraint, these traders also face solvency constraints in the form of a lower bound on the value of their net asset position, to rule out Ponzi games:

$$
a_{t}\left(z^{t+1}, \eta^{t+1}\right) \geq \underline{M}\left(\eta^{t+1}, z^{t+1}\right)
$$

Active traders The active traders face the additional constraint that $a_{t}\left(z^{t+1}, \eta^{t+1}\right)$ be measurable with respect to $\left(z^{t+1}, \eta^{t}\right)$ :

$$
a_{t}\left(z^{t+1},\left[\eta^{t}, \eta_{t+1}\right]\right)=a_{t}\left(z^{t+1},\left[\eta^{t}, \tilde{\eta}_{t+1}\right]\right)
$$

for all $z^{t+1}, \eta^{t}$, and $\eta_{t+1}, \tilde{\eta}_{t+1} \in N$. We refer this as the active trader's measurability condition.

The active trader's problem is to choose $\left\{c\left(z^{t}, \eta^{t}\right), a_{t}\left(z^{t+1}, \eta^{t+1}\right)\right\}, a_{0}\left(z^{1}, \eta^{1}\right)$ to maximize his expected utility (2.1) subject to the constraints in (2.2-2.4) and the measurability constraint in (2.5)

Passive traders The only source of state-contingency in the passive trader's net wealth position is the return on his fixed-weighted portfolio of stocks and bonds. Hence, his contingent bond payoff in each state has to be proportional to the return on the portfolio. Let $R^{p}\left(\varpi, z^{t}\right)$ denote the return

\footnotetext{
${ }^{5}$ Of course, in this approach, the contingent bond positions have to add up to diversifiable income in equilibrium.
} 
on the passive trader's total portfolio with fixed weight $\varpi$ for equities. We can state the passive trader's measurability condition as:

$$
\frac{a_{t}\left(\left[z^{t}, z_{t+1}\right],\left[\eta^{t}, \eta_{t+1}\right]\right)}{R^{p}\left(\varpi,\left[z^{t}, z_{t+1}\right]\right)}=\frac{a_{t}\left(\left[z^{t}, \tilde{z}_{t+1}\right],\left[\eta^{t}, \tilde{\eta}_{t+1}\right]\right)}{R^{p}\left(\varpi,\left[z^{t}, \widetilde{z}_{t+1}\right]\right)}
$$

for all $z^{t}, \eta^{t}, z_{t+1}, \tilde{z}_{t+1} \in Z$, and $\eta_{t+1}, \tilde{\eta}_{t+1} \in N$.

The passive trader's problem is to choose $\left\{c\left(z^{t}, \eta^{t}\right), a_{t}\left(z^{t+1}, \eta^{t+1}\right)\right\}, a_{0}\left(z^{1}, \eta^{1}\right)$ to maximize his expected utility (2.1) subject to the constraints in (2.2.2.4) and the measurability constraint in (2.6).

We distinguish between two types of passive traders: non-participants (denoted $n p$ ), who invest in the risk-free one-period bond, and buy-and-hold traders (denoted $b h$ ), who hold positive amounts of equity in their portfolio. The portfolio return of the non-participant $(\varpi=0)$ is the risk-free rate: $R^{p}\left(0, z^{t}\right)=R^{f}\left(z^{t-1}\right)$. The portfolio return of the buy-and-hold trader is the return on a portfolio with a constant fraction $\varpi$ invested in equities.

Importantly, the active traders can fully hedge against aggregate shocks. We can think of them as having access to a menu of stocks and bonds that is rich enough to span the aggregate shocks. In our quantitative analysis, since we have only two aggregate states, active traders are effectively only trading the stock and the bond, and hence we can back out their portfolio weights. The passive traders cannot fully hedge against either aggregate or idiosyncratic risk.

\subsection{Equilibrium}

A fraction $\mu_{z}$ of households are active traders. The other households are passive traders who can only trade a fixed-weighted portfolio of bonds and stocks. A fraction $\mu_{b h}$ of passive traders, the buy-and-hold traders, can only trade a fixed-weighted portfolio of stocks and bonds, and a fraction $\mu_{n p}$, the non-participants, can trade only bonds. The market clearing condition in the contingent bond market in each aggregate state $z^{t}$ is given by:

$$
\sum_{\eta^{t}}\left[\mu_{z} a_{t-1}^{z}\left(z^{t}, \eta^{t}\right)+\mu_{b h} a_{t-1}^{b h}\left(z^{t}, \eta^{t}\right)+\mu_{n p} a_{t-1}^{n p}\left(z^{t}, \eta^{t}\right)\right] \pi\left(\eta^{t} \mid z^{t}\right)=(1-\gamma) Y\left(z^{t}\right)
$$

where $a^{z}, a^{h}$, and $a^{n p}$ denote the bond holdings of the active traders, the buy-and-hold traders and the non-participants respectively.

Definition 2.1. A sequential equilibrium for this economy is defined in the standard way. It consists of a list of contingent bond holdings $\left\{a_{t-1}^{j}\left(z^{t}, \eta^{t}\right)\right\}, j \in\{z, b h, n p\}$, a consumption allocation $\left\{c^{j}\left(z^{t}, \eta^{t}\right)\right\}, j \in\{z, b h, n p\}$, and a list of contingent bond prices $\left\{q\left(z_{t+1}, z^{t}\right)\right\}$ such that: (i) given these prices, a household's asset and consumption choices maximize her expected utility subject to 
the budget constraints, the solvency constraints and the measurability constraints for her trading technology $j \in\{z, b h, n p\}$, and (ii) the contingent bond market clears in each node $z^{t}$.

The next section analytically characterizes the household consumption function and the equilibrium pricing kernel in terms of the distribution of the household's stochastic multipliers.

\section{Solving for Equilibrium Allocations and Prices}

This section reformulates the household's problem in terms of a single present-value budget constraint, and sequences of measurability constraints and solvency constraints. We show how to use the cumulative multipliers on these constraints in the saddle point problem as stochastic weights that fully characterize equilibrium allocations and prices. Cuoco and He (2001) were the first to use a similar stochastic weighting scheme in a discrete-time setup.

From these contingent bond prices in the sequential equilibrium, we can back out the state prices recursively as follows:

$$
\pi\left(z^{t}\right) P\left(z^{t}\right)=q\left(z_{t}, z^{t-1}\right) q\left(z_{t-1}, z^{t-2}\right) \cdots q\left(z_{1}, z^{0}\right) q\left(z_{0}\right)
$$

We use $\widetilde{P}\left(z^{t}, \eta^{t}\right)$ to denote the Arrow-Debreu prices $P\left(z^{t}\right) \pi\left(z^{t}, \eta^{t}\right)$. Let $m\left(z^{t+1} \mid z^{t}\right)=P\left(z^{t+1}\right) / P\left(z^{t}\right)$ denote the stochastic discount factor that prices any random payoffs. We assume there is always a non-zero measure of active traders. This guarantees the uniqueness of pricing of payoffs contingent on aggregate events.

By repeated backward substitution of the sequential budget constraint, and using the recursive definition of the state prices in equation (3.1), we recover the static budget constraint:

$$
\sum_{t \geq 1} \sum_{\left(z^{t}, \eta^{t}\right)} \widetilde{P}\left(z^{t}, \eta^{t}\right)\left[\gamma Y\left(z^{t}\right) \eta_{t}-c\left(z^{t}, \eta^{t}\right)\right]+a_{-1}\left(z^{0}\right) \geq 0
$$

By the same token, repeated substitution delivers the following 'static version' of the measurability constraints for active traders in node $\left(z^{t}, \eta^{t}\right)$ :

$$
\sum_{\tau \geq t} \sum_{\left(z^{\tau}, \eta^{\tau}\right) \succeq\left(z^{t}, \eta^{t}\right)} \widetilde{P}\left(z^{\tau}, \eta^{\tau}\right)\left[\gamma Y\left(z^{\tau}\right) \eta_{\tau}-c\left(z^{\tau}, \eta^{\tau}\right)\right]=-\widetilde{P}\left(z^{t}, \eta^{t}\right) a_{t-1}\left(z^{t}, \eta^{t-1}\right)
$$

For passive traders, we simply replace $a_{t-1}\left(z^{t}, \eta^{t-1}\right)$ on the right hand side by $a_{t-1}\left(z^{t-1}, \eta^{t-1}\right) R^{p}\left(\varpi, z^{t}\right)$. The extension to static solvency constraints is obvious:

$$
-\sum_{\tau \geq t} \sum_{\left(z^{\tau}, \eta^{\tau}\right) \succeq\left(z^{t}, \eta^{t}\right)} \widetilde{P}\left(z^{\tau}, \eta^{\tau}\right)\left[\gamma Y\left(z^{\tau}\right) \eta_{\tau}-c\left(z^{\tau}, \eta^{\tau}\right)\right] \geq \underline{M}\left(\eta^{t}, z^{t}\right)
$$


In the static optimization problem, each household chooses a consumption plan to maximize her expected utility subject to the static budget constraints in (3.2), the measurability constraints for her trading technology $j \in\{z, b h, n p\}$ in (3.3) and the solvency constraints in (3.4). A static equilibrium for this economy is defined in the standard way.

Definition 3.1. A static equilibrium consists of a consumption allocation $\left\{c^{j}\left(z^{t}, \eta^{t}\right)\right\}, j \in\{z$, bh, np $\}$ and a list of state prices $P\left(z^{t}, \eta^{t}\right)$ such that: (i) given these prices, a household's asset and consumption choices maximize her expected utility subject to the static budget constraints in (3.2), the solvency constraints in (3.4) and the measurability constraints for her trading technology $j \in$ $\{z, b h, n p\}$ in (3.3), and the goods markets clears in each node $z^{t}$.

While every time-zero trading equilibrium has an equivalent sequential trading equilibrium, a sequential trading equilibrium only has an equivalent time-zero trading equilibrium if the present value of the aggregate endowment is finite under the constructed prices, or:

Condition 3.1. Interest rates are said to be high enough iff

$$
\sum_{t>0} \sum_{\left(z^{t}, \eta^{t}\right)} Y\left(z^{t}\right) \pi\left(z^{t}, \eta^{t}\right) P\left(z^{t}, \eta^{t}\right)<\infty
$$

This then implies that the present value of any individual's initial endowment is also finite since the idiosyncratic shock is assumed to have finite support. In economies with sequential trading and solvency constraints, it does not immediately follow that endowments are finitely valued in equilibrium (see Hellwig and Lorenzoni (2009)), because sequential budget and measurability constraints are implicity backward-looking, while the time-zero trading economy has forward looking versions of these constraints.

Proposition 3.1. If condition (3.1) is satisfied, the sequential equilibrium allocations and prices can be implemented as an equilibrium of the static economy. Let the contingent bond positions $\left\{a_{t-1}^{j}\left(z^{t}, \eta^{t}\right)\right\}, j \in\{z, b h, n p\}$, the consumption allocation $\left\{c^{j}\left(z^{t}, \eta^{t}\right)\right\}, j \in\{z, b h, n p\}$, and the contingent bond prices $\left\{q\left(z_{t+1}, z^{t}\right)\right\}$ be a sequential equilibrium. Then the state prices $\left\{P\left(z^{t}, \eta^{t}\right)\right\}$ implied by $\left\{q\left(z_{t+1}, z^{t}\right)\right\}$ and the consumption allocation $\left\{c^{j}\left(z^{t}, \eta^{t}\right)\right\}$ constitute a static equilibrium.

Given these results, we can restate the household's problem as one of choosing an entire consumption plan from a restricted budget set. The central result is a martingale condition for the stochastic multipliers.

\subsection{Characterizing Equilibrium Allocations and Prices}

In the static economy, markets open only once at time zero. The household chooses a consumption plan and a net wealth plan subject to a single budget constraint at time zero, as well as an infinite 
number of solvency constraints and measurability constraints. These measurability constraints act as direct restrictions on the household budget set. This optimization problem has a convex constraint set, as can easily be verified, because any convex combination of two allocations that satisfy the budget constraint, the solvency constraints and the measurability constraints, also satisfies these constraints. As a result of the convexity, if in addition we assume that the Markov process for $(z, \eta)$ satisfies the Feller condition and that the utility function is bounded, then (i) Lagrangian multipliers exist for the budget constraint, the solvency and measurability constraints such that a saddle point can be found for an optimum of the static optimization problem (see proposition 2 in Marcet and Marimon (1999)) and (ii) the saddle point problem is well-defined in its own right, i.e. it has a solution (see proposition 3 in Marcet and Marimon (1999)). The boundedness of utility can be achieved by forcing the consumption shares (as a share of the aggregate endowment) to lie on a bounded set. This is what we do in the computational section (see separate appendix for details).

We start off by considering the active traders.

Active Traders Let $\chi$ denote the multiplier on the present-value budget constraint, let $\nu\left(z^{t}, \eta^{t}\right)$ denote the multiplier on the measurability constraint in node $\left(z^{t}, \eta^{t}\right)$, and, finally, let $\varphi\left(z^{t}, \eta^{t}\right)$ denote the multiplier on the solvency constraint. The saddle point problem of an active trader can be stated as:

$$
\begin{aligned}
& L=\min _{\{\chi, \nu, \varphi\}} \max _{\left\{c, a_{-1}\right\}} \sum_{t=1}^{\infty} \beta^{t} \sum_{\left(z^{t}, \eta^{t}\right)} u\left(c\left(z^{t}, \eta^{t}\right)\right) \pi\left(z^{t}, \eta^{t}\right) \\
& +\chi\left\{\sum_{t \geq 1} \sum_{\left(z^{t}, \eta^{t}\right)} \widetilde{P}\left(z^{t}, \eta^{t}\right)\left[\gamma Y\left(z^{t}\right) \eta_{t}-c\left(z^{t}, \eta^{t}\right)\right]+a_{-1}\left(z^{0}\right)\right\} \\
& +\sum_{t \geq 1} \sum_{\left(z^{t}, \eta^{t}\right)} \nu\left(z^{t}, \eta^{t}\right)\left\{\sum_{\tau \geq t} \sum_{\left(z^{\tau}, \eta^{\tau}\right) \succeq\left(z^{t}, \eta^{t}\right)} \widetilde{P}\left(z^{\tau}, \eta^{\tau}\right)\left[\gamma Y\left(z^{\tau}\right) \eta_{\tau}-c\left(z^{\tau}, \eta^{\tau}\right)\right]+\widetilde{P}\left(z^{t}, \eta^{t}\right) a_{t-1}\left(z^{t}, \eta^{t-1}\right)\right\} \\
& +\sum_{t \geq 1} \sum_{\left(z^{t}, \eta^{t}\right)} \varphi\left(z^{t}, \eta^{t}\right)\left\{-\underline{M_{t}}\left(z^{t}, \eta^{t}\right) \widetilde{P}\left(z^{t}, \eta^{t}\right)-\sum_{\tau \geq t} \sum_{\left(z^{\tau}, \eta^{\tau}\right) \succeq\left(z^{t}, \eta^{t}\right)} \widetilde{P}\left(z^{\tau}, \eta^{\tau}\right)\left[\gamma Y\left(z^{\tau}\right) \eta_{\tau}-c\left(z^{\tau}, \eta^{\tau}\right)\right]\right\},
\end{aligned}
$$

Following Marcet and Marimon (1999), we can construct new weights for this Lagrangian as follows. First, we define the initial cumulative multiplier to be equal to the multiplier on the budget constraint: $\zeta_{0}=\chi$. Second, the multiplier evolves over time as follows for all $t \geq 1$ :

$$
\zeta\left(z^{t}, \eta^{t}\right) \equiv \zeta\left(z^{t-1}, \eta^{t-1}\right)+\nu\left(z^{t}, \eta^{t}\right)-\varphi\left(z^{t}, \eta^{t}\right)
$$


Substituting for these cumulative multipliers in the Lagrangian, we recover the following expression for the constraints component of the Lagrangian for active traders:

$$
\begin{aligned}
& \sum_{t \geq 1} \sum_{z^{t}, \eta^{t}} \widetilde{P}\left(z^{t}, \eta^{t}\right)\left\{\zeta\left(z^{t}, \eta^{t}\right)\left(\gamma \eta^{t} Y\left(z^{t}\right)-c\left(z^{t}, \eta^{t}\right)\right)+\nu\left(z^{t}, \eta^{t}\right) a_{t-1}\left(z^{t}, \eta^{t-1}\right)-\varphi\left(z^{t}, \eta^{t}\right) \underline{M}\left(z^{t}, \eta^{t}\right)\right\} \\
& +\chi a_{-1}\left(z^{0}\right) .
\end{aligned}
$$

This is a standard convex programming problem -the constraint set is still convex, even with the measurability conditions and the solvency constraints. The first order conditions are necessary and sufficient. The first order condition for consumption implies that the cumulative multiplier measures the household's discounted marginal utility relative to the state price $P\left(z^{t}\right)$ :

$$
\frac{\beta^{t} u^{\prime}\left(c\left(z^{t}, \eta^{t}\right)\right)}{\zeta\left(z^{t}, \eta^{t}\right)}=P\left(z^{t}\right)
$$

This condition is common to all of our traders irrespective of their trading technology because differences in their trading technology do not affect the way in which $c\left(z^{t}, \eta^{t}\right)$ enters the objective function or the constraint portion of the Lagrangian. Hence, along the optimal consumption path, the marginal utility of households is proportional to their cumulative multiplier, regardless of their trading technology.

The first order condition with respect to net wealth $a_{t}\left(z^{t+1}, \eta^{t}\right)$ is given by:

$$
E\left[\nu\left(z^{t+1}, \eta^{t+1}\right) \mid z^{t+1}\right]=\sum_{\eta^{t+1} \succ \eta^{t}} \nu\left(z^{t+1}, \eta^{t+1}\right) \pi\left(z^{t+1}, \eta^{t+1}\right) P\left(z^{t+1}\right)=0, \forall\left(\eta^{t}, z^{t+1}\right) .
$$

We refer to this as the martingale condition. This condition is specific to the trading technology. For the active trader, it implies that the average measurability multiplier across idiosyncratic states $\eta^{t+1}$ is zero since $P\left(z^{t+1}\right)$ is independent of $\eta^{t+1}$. In each aggregate node $z^{t+1}$, the household's marginal utility innovations not driven by the solvency constraints $\left(\nu_{t+1}\right)$ have to be white noise. The trader has high marginal utility growth in low $\eta$ states and low marginal utility growth in high $\eta$ states, but these innovations to marginal utility growth average out to zero in each node $\left(z^{t}, z_{t+1}\right)$. If the solvency constraints do bind, then the cumulative multipliers decrease on average:

$$
E\left\{\zeta\left(z^{t+1}, \eta^{t+1}\right) \mid z^{t+1}\right\} \leq \zeta\left(z^{t}, \eta^{t}\right)
$$

which we obtained by substituting (3.5) into the first-order condition (3.7). Hence our recursive multipliers are a bounded super-martingale. The cumulative multiplier is a martingale if the solvency constraints do not bind for any $\eta^{t+1} \succ \eta^{t}$ given $z^{t+1}$.

The common characteristic for all unconstrained active traders is that their marginal utility 
innovations are orthogonal to any aggregate variables, because we know that $E\left[\nu_{t+1} \mid z^{t+1}\right]=0$ in each node $z^{t+1}$. Below, we explore the implications of this finding, but first, we show that buyand-hold traders and non-participants satisfy the same martingale condition, but with respect to a different measure.

Passive Traders For the passive investors, the constraints portion of the Lagrangian looks somewhat different:

$$
\begin{aligned}
& +\sum_{t \geq 1} \sum_{z^{t}, \eta^{t}} \widetilde{P}\left(z^{t}, \eta^{t}\right)\left[\zeta\left(z^{t}, \eta^{t}\right)\left(\gamma \eta^{t} Y\left(z^{t}\right)-c\left(z^{t}, \eta^{t}\right)\right)+\nu\left(z^{t}, \eta^{t}\right) a_{t-1}\left(z^{t-1}, \eta^{t-1}\right) R^{p}\left(\varpi, z^{t}\right)\right] \\
& -\sum_{t \geq 1} \sum_{z^{t}, \eta^{t}} \widetilde{P}\left(z^{t}, \eta^{t}\right)\left[\varphi\left(z^{t}, \eta^{t}\right) \underline{M}\left(z^{t}, \eta^{t}\right)\right]+\chi a_{-1}\left(z^{0}\right) .
\end{aligned}
$$

The other components of the Lagrangian and the law of motion for the cumulative multiplier in (3.5) are unchanged. The first order condition with respect to $a_{t}\left(z^{t+1}, \eta^{t+1}\right)$ is given by:

$$
\sum_{z^{t+1} \succ z^{t}, \eta^{t+1} \succ \eta^{t}} \nu\left(z^{t+1}, \eta^{t+1}\right) R^{p}\left(\varpi, z^{t+1}\right) \pi\left(z^{t+1}, \eta^{t+1}\right) P\left(z^{t+1}\right)=0 .
$$

The other conditions are identical. Using the recursive definition of the multipliers, the first order condition in (3.8) can be stated as:

$$
\zeta\left(z^{t}, \eta^{t}\right) \geq \sum_{z^{t+1} \succ z^{t}, \eta^{t+1} \succ \eta^{t}} \zeta\left(z^{t+1}, \eta^{t+1}\right) \widetilde{\pi}\left(z^{t+1}, \eta^{t+1} \mid z^{t}, \eta^{t}\right), \forall\left(\eta^{t}, z^{t}\right)
$$

where the twisted probabilities are defined as:

$$
\widetilde{\pi}\left(z^{t+1}, \eta^{t+1} \mid z^{t}, \eta^{t}\right)=\frac{m\left(z^{t+1} \mid z^{t}\right) R^{p}\left(\varpi, z^{t+1}\right)}{E\left\{m\left(z^{t+1} \mid z^{t}\right) R^{p}\left(\varpi, z^{t+1}\right) \mid z^{t}\right\}} \pi\left(z^{t+1}, \eta^{t+1} \mid z^{t}, \eta^{t}\right),
$$

Relative to these twisted probabilities, the passive trader's multipliers are a super-martingale. Moreover, when the solvency constraints do not bind, the multipliers satisfy a martingale condition. Different portfolio rules lead to differences in the rates of return and the twisting factor. In the case of non-participants, $R^{p}\left(0, z^{t+1}\right)$ is the risk-free return $R^{f}\left(z^{t}\right)$, which is measurable with respect to the aggregate history at $t$.

Euler equations These martingale conditions enforce the Euler inequalities for the different traders: (i) the passive traders: $u^{\prime}\left(c_{t}\right) \geq \beta E_{t}\left\{R_{t+1}^{p}\left(\varpi, z^{t+1}\right) u^{\prime}\left(c_{t+1}\right)\right\}$,(ii) the active traders : $u^{\prime}\left(c_{t}\right) \geq \beta E_{t}\left\{u^{\prime}\left(c_{t+1}\right) \frac{P\left(z^{t}\right)}{P\left(z^{t+1}\right)} \mid z^{t+1}\right\}$. In the Euler equation of the active traders, we are averaging across idiosyncratic states $\eta_{t+1}$ in the next period, conditional on some aggregate node $z^{t+1}$. These 
trading-technology-specific Euler equations follow directly from the martingale conditions, which depend on the trading technologies, and the first order condition for consumption, which do not. All households share the same first order condition for consumption, regardless of their trading technology. This implies that we can derive a consumption sharing rule and an aggregation result for prices.

\subsection{Aggregate Multiplier}

We can characterize equilibrium prices and allocations using the household's multipliers and the aggregate multipliers. We use $C\left(z^{t}\right)$ to denote aggregate consumption.

Proposition 3.2. The household consumption share, for all traders is given by

$$
\frac{c\left(z^{t}, \eta^{t}\right)}{C\left(z^{t}\right)}=\frac{\zeta\left(z^{t}, \eta^{t}\right)^{\frac{-1}{\alpha}}}{h\left(z^{t}\right)}, \text { where } h\left(z^{t}\right)=\sum_{\eta^{t}} \zeta\left(z^{t}, \eta^{t}\right)^{\frac{-1}{\alpha}} \pi\left(\eta^{t} \mid z^{t}\right)
$$

The SDF is given by the Breeden-Lucas SDF and a multiplicative adjustment:

$$
m\left(z^{t+1} \mid z^{t}\right)=\beta\left(\frac{C\left(z^{t+1}\right)}{C\left(z^{t}\right)}\right)^{-\alpha}\left(\frac{h\left(z^{t+1}\right)}{h\left(z^{t}\right)}\right)^{\alpha}
$$

Proof. The consumption sharing rule follows directly from the ratio of the first order conditions and the market clearing condition. Condition (3.6) implies that $c\left(z^{t}, \eta^{t}\right)=u^{\prime-1}\left[\frac{\zeta\left(z^{t}, \eta^{t}\right) P\left(z^{t}\right)}{\beta^{t}}\right]$. In addition, the sum of individual consumptions aggregate up to aggregate consumption: $C\left(z^{t}\right)=$ $\sum_{\eta^{t}} c\left(z^{t}, \eta^{t}\right) \pi\left(\eta^{t} \mid z^{t}\right)$, where $\pi\left(\eta^{t} \mid z^{t}\right)=\pi\left(\eta^{t}, z^{t}\right) / \pi\left(z^{t}\right)$ also denotes the fraction of agents in node $z^{t}$ who have drawn $\eta^{t}$. This implies that the consumption share of the individual with history $\left(z^{t}, \eta^{t}\right)$ is

$$
\frac{c\left(z^{t}, \eta^{t}\right)}{C\left(z^{t}\right)}=\frac{u^{\prime-1}\left[\frac{\zeta\left(z^{t}, \eta^{t}\right) P\left(z^{t}\right)}{\beta^{t}}\right]}{\sum_{\eta^{t}} u^{\prime-1}\left[\frac{\zeta\left(z^{t}, \eta^{t}\right) P\left(z^{t}\right)}{\beta^{t}}\right] \pi\left(\eta^{t} \mid z^{t}\right)} .
$$

With CRRA preferences, this implies that the consumption share is given by equation (3.10). Hence, the $-1 / \alpha^{\text {th }}$ moment of the multipliers summarizes the risk sharing within this economy. We refer to this moment of the multipliers simply as the aggregate multiplier.

Making use of (3.2) and the individual first-order condition, we get that

$$
\beta^{t} u^{\prime}\left[\frac{u^{-1}\left[\beta^{-t} \zeta\left(z^{t}, \eta^{t}\right) P\left(z^{t}\right)\right]}{\sum_{\eta^{t}} u^{\prime-1}\left[\beta^{-t} \zeta\left(z^{t}, \eta^{t}\right) P\left(z^{t}\right)\right] \pi\left(\eta^{t} \mid z^{t}\right)} C\left(z^{t}\right)\right]=P\left(z^{t}\right) \zeta\left(z^{t}, \eta^{t}\right)
$$


If $u^{\prime-1}$ is homogeneous, which it is with CRRA preferences, then this expression simplifies to

$$
\beta^{t} u^{\prime}\left[\frac{C\left(z^{t}\right)}{\sum_{\eta^{t}} u^{\prime-1}\left[\zeta\left(z^{t}, \eta^{t}\right)\right] \pi\left(\eta^{t} \mid z^{t}\right)}\right]=P\left(z^{t}\right)
$$

which implies that the ratio of the state prices is given by

$$
\frac{\beta u^{\prime}\left[\frac{C\left(z^{t+1}\right)}{\left.\sum_{\eta^{t} u^{\prime-1}\left[\zeta\left(z^{t+1}, \eta^{t+1}\right)\right] \pi\left(\eta^{t+1} \mid z^{t+1}\right)}\right]}\right.}{u^{\prime}\left[\frac{C\left(z^{t}\right)}{\sum_{\eta^{t}} u^{\prime-1}\left[\zeta\left(z^{t}, \eta^{t}\right)\right] \pi\left(\eta^{t} \mid z^{t}\right)}\right]}=\frac{P\left(z^{t+1}\right)}{P\left(z^{t}\right)} .
$$

Given that we are assuming CRRA preferences, this implies the expression for the SDF in equation (3.11). The equilibrium SDF is the standard Breeden-Lucas SDF times the growth rate of the aggregate multiplier. This aggregate multiplier reflects the aggregate shadow cost of the measurability and the solvency constraints faced by households.

This aggregation result extends the complete market result in Chien and Lustig (2009) to the case of incomplete markets and heterogeneous trading technologies. This proposition directly implies that an equilibrium for this class of incomplete market economies can be completely characterized by a process for these cumulative multipliers $\left\{\zeta\left(\eta^{t}, z^{t}\right)\right\}$, and by the associated aggregate multiplier process $\left\{h\left(z^{t}\right)\right\}$. Section 4 describes a method to solve for these multipliers. We can use the consumption sharing rule and the martingale condition to highlight the main features of the savings and investment behavior of active traders.

Other Trading Technologies While we restrict ourselves to these trading technologies, our framework is flexible enough to handle other trading technologies. The most obvious active technology is the complete markets one which allows for trading bonds contingent on both aggregate and idiosyncratic shock realizations. In this case, there is no measurability constraint. Another active technology precludes direct trade in state contingent bonds, but it allows for optimally choosing the portfolio of equities and non-contingent bonds in each period. Since this trader's financial wealth tomorrow is determined by his savings and portfolio choice today $\varpi\left(z^{t}, \eta^{t}\right)$, he still faces the same measurability restriction as the passive trader (see equation (2.6)). However, the ability to optimally choose $\varpi\left(z^{t}, \eta^{t}\right)$ introduces an additional first-order condition of the form

$$
\sum_{z^{t+1} \succ z^{t}, \eta^{t+1} \succ \eta^{t}} \nu\left(z^{t+1}, \eta^{t+1}\right) \frac{d}{d \varpi} R^{p}\left(\varpi\left(z^{t}, \eta^{t}\right), z^{t+1}\right) \pi\left(z^{t+1}, \eta^{t+1}\right) P\left(z^{t+1}\right)=0 .
$$

This condition implies that he is choosing $\varpi\left(z^{t}, \eta^{t}\right)$ to relax his measurability constraint as much as possible. In the case with only two aggregate states that we consider in the quantitative section, 
there is of course no difference between this stock/bond trading technology and the active trading technology we consider in our paper.

Savings Investment Behavior The active trader increases his consumption as a share of the aggregate endowment in aggregate states with low state prices, thus helping to clear the market.

Corrolary 3.1. If the state price is low and $h\left(z^{t+1}\right) / h\left(z^{t}\right) \leq 1$, the unconstrained active trader's consumption share increases on average across $\eta^{t+1}$ states in the next period. If the state price is high and $h\left(z^{t+1}\right) / h\left(z^{t}\right)>1$, her consumption share can increase or decrease.

To understand this results, it helps to consider a hypothetical complete trader, who faces no measurability restrictions and hence has a constant multiplier $\zeta$ in the absence of binding solvency constraints, simply because his martingale condition reads as $\nu=0$. This complete trader changes his consumption share at a rate $-h\left(z^{t+1}\right) / h\left(z^{t}\right)$ in each $\eta^{t+1}, z^{t+1}$ state in the next period. This is an even more aggressive trading strategy; our active trader is more conservative because he still faces idiosyncratic risk.

The martingale condition for active traders puts tight restrictions on the joint distribution of returns and consumption growth. Using the SDF expression in (3.11), we can state the martingale condition as $E_{t}\left[m_{t+1} \nu_{t+1}\right]=0$ for non-participants and active traders. This gives rise to the following expression for marginal utility growth of an unconstrained trader:

$$
E_{t}\left[\frac{\zeta_{t+1}}{\zeta_{t}}\right]=1-E_{t}\left[m_{t+1}\right]^{-1} \operatorname{cov}_{t}\left[\frac{\zeta_{t+1}}{\zeta_{t}}, m_{t+1}\right]
$$

The covariance term drops out for active traders because $E\left[\nu_{t+1} \mid z^{t+1}\right]=0$ in each node $z^{t+1}$. This orthogonality condition is the hallmark of an "active trading" strategy. Active traders increase their consumption growth when state prices are lower than in the representative agent model, and they decrease consumption growth when state prices are higher than in the representative agent model, thus satisfying the orthogonality condition. However, this covariance term is non-zero for passive traders: their trading technology does not allow them to adjust consumption growth in different aggregate states of the world.

\subsection{Aggregate Wealth in Different Segments}

We define the aggregate multiplier for each trading segment $j \in\{z, b h, n p\}$ by aggregating across all households in that segment: $h^{j}\left(z^{t}\right)=\sum_{\eta^{t}} \zeta^{j}\left(z^{t}, \eta^{t}\right)^{\frac{-1}{\alpha}} \pi\left(\eta^{t} \mid z^{t}\right)$. By aggregating household wealth across all households in a trading segment $j$, we can define the aggregate wealth for each group of 
traders $j \in\{z, b h, n p\}$ :

$$
A^{j}\left(z^{t}\right)=\left[\frac{h^{j}\left(z^{t}\right)}{h\left(z^{t}\right)}-\gamma \mu^{j}\right] C\left(z^{t}\right)+\sum_{z^{t+1}} \frac{\pi\left(z^{t+1}\right) P\left(z^{t+1}\right)}{\pi\left(z^{t}\right) P\left(z^{t}\right)} A^{j}\left(z^{t+1}\right),
$$

where we use the linearity of the pricing functional. Finally, total aggregate wealth equals the market portfolio: $\sum_{j} A^{j}\left(z^{t}\right)=\left[\omega\left(z^{t}\right)+(1-\gamma) Y\left(z^{t}\right)\right]$. This follows directly from market clearing. The measurability restrictions on the household wealth function in turn imply restrictions on the aggregate savings share of each trader group. These restrictions will help us understand the results in the quantitative section.

For the remainder of the paper, we focus on buy-and-hold investors who hold debt and equity in proportion to the market portfolio. These buy-and-hold trader invests a fraction $\psi /(1+\psi)$ in bonds and the remainder $1 /(1+\psi)$ in equity. Hence, their portfolio return $R^{p}\left(1 /(1+\psi), z^{t}\right)$ is the return on a claim to all diversifiable income. This portfolio is a natural benchmark, because this portfolio is the optimal one (and it is constant) in the case without non-participants in the IID economy. In subsection 6.3, we vary the equity holdings of the buy-and-hold investors.

Because the buy-and-hold traders hold the market, they do not bear any of the residual aggregate risk, (in terms of their savings share) created by non-participants.

Proposition 3.3. Conditional on $z^{t-1}$, the aggregate wealth share $\frac{A^{\text {bh }}\left(z^{t}\right)}{\left[\omega\left(z^{t}\right)+(1-\gamma) Y\left(z^{t}\right)\right]}$ of buy-and-hold traders with $\varpi=1 /(1+\psi)$ cannot depend on $z_{t}$.

Since the measurability constraints are satisfied for the individual household's wealth, they also need to be satisfied for aggregate wealth. So by the LLN:

$$
\frac{A^{b h}\left(\left[z^{t-1}, z_{t}\right]\right)}{\left[(1-\gamma) Y\left(\left[z^{t-1}, z_{t}\right]\right)+\omega\left(\left[z^{t-1}, z_{t}\right]\right)\right]}=\frac{A^{b h}\left(\left[z^{t-1}, \tilde{z}_{t}\right]\right)}{\left[(1-\gamma) Y\left(\left[z^{t-1}, \tilde{z}_{t}\right]\right)+\omega\left(\left[z^{t-1}, \tilde{z}_{t}\right]\right)\right]}
$$

where we have used the fact that the denominator is measurable w.r.t. $z^{t}$. The household measurability condition implies that the aggregate savings of the buy-and-hold traders be proportional to the diversifiable income claim in all the aggregate states $z_{t}$. This is not surprising, since the buy-and-hold traders hold the market portfolio.

Constant aggregate consumption shares $\frac{h^{b h}\left(z^{t}\right)}{h\left(z^{t}\right)}$ for the buy-and-hold traders would trivially satisfy this aggregate measurability constraint. Since any other consumption sequence would yield less in total expected utility, this implies that the aggregate consumption share of the buy-and-hold traders is constant.

Corrolary 3.2. Conditional on $z^{t-1}$, the aggregate consumption share $\frac{h^{b h}\left(z^{t}\right)}{h\left(z^{t}\right)}$ of the buy-and-hold traders with $\varpi=1 /(1+\psi)$ cannot depend on $z_{t}$.

Second, the non-participants create residual aggregate risk. 
Proposition 3.4. Conditional on $z^{t-1}$, the aggregate wealth share of non-participants $\frac{A^{n p}\left(z^{t}\right)}{\left[\omega\left(z^{t}\right)+(1-\gamma) Y\left(z^{t}\right)\right]}$ is inversely proportional to the aggregate endowment growth rate

The proof is obvious and hence omitted. This follows directly from the measurability condition of the non-participant households, which implies that their individual and hence their aggregate wealth level cannot depend upon $z_{t+1}$.

Finally, since the buy-and-hold traders have (conditionally) constant savings shares, and the non-participant traders have counter-cyclical wealth shares, regardless of the $\left\{h\left(z^{t}\right)\right\}$ process, there cannot be an equilibrium without active traders. The market simply cannot be cleared without active traders, if there are non-participants.

The next section derives a recursive set of updating rules for the aggregate multipliers.

\section{Computation}

This section describes a recursive, computational method that exploits the martingale conditions for different traders and the consumption sharing rule to compute the equilibrium allocations and prices.

\subsection{System of Equations}

To allow us to compute equilibrium allocations and prices for a calibrated version of this economy, we recast our optimality conditions in recursive form. Making use of the consumption sharing rule, we can express the household's present discounted value of future consumption minus future labor income or wealth as a function of the individual's multiplier:

$$
\begin{aligned}
a_{t}\left(\zeta\left(z^{t}, \eta^{t}\right) ; z^{t}, \eta^{t}\right) & =\left[\frac{\zeta\left(z^{t}, \eta^{t}\right)^{\frac{-1}{\alpha}}}{h\left(z^{t}\right)}-\gamma \eta_{t}\right] C\left(z^{t}\right) \\
& +\sum_{z^{t+1}, \eta^{t+1}} \frac{\pi\left(z^{t+1}, \eta^{t+1}\right) P\left(z^{t+1}\right)}{\pi\left(z^{t}, \eta^{t}\right) P\left(z^{t}\right)} a_{t+1}\left(\zeta\left(z^{t+1}, \eta^{t+1}\right) ; z^{t+1}, \eta^{t+1}\right) .
\end{aligned}
$$

We refer to this as the recursive wealth equation. This recursive expression holds for all of our different asset traders.

The Kuhn-Tucker condition on the solvency constraint reads as:

$$
\varphi\left(\eta^{t+1}, z^{t+1}\right)\left[-a_{t}\left(\zeta\left(z^{t+1}, \eta^{t+1}\right) ; z^{t+1}, \eta^{t+1}\right)+\underline{M}\left(z^{t+1}, \eta^{t+1}\right)\right]=0
$$

This condition is common to all traders, regardless of the trading technology. However, the measurability and optimality conditions depend upon the trading technology. 
Active Traders We start with the case of active traders. Let $a^{z}(\cdot)$ denote the active trader's wealth. The measurability constraint requires that the discounted value of the future surpluses be equal for each future $\eta^{t+1}$, or

$$
a_{t+1}^{z}\left(\zeta\left(z^{t+1},\left[\eta^{t}, \eta_{t+1}\right]\right) ; z^{t+1},\left[\eta^{t}, \eta_{t+1}\right]\right)=a_{t+1}^{z}\left(\zeta\left(z^{t+1},\left[\eta^{t}, \tilde{\eta}_{t+1}\right]\right) ; z^{t+1},\left[\eta^{t}, \tilde{\eta}_{t+1}\right]\right)
$$

for all $\left[\eta^{t}, \eta_{t+1}\right],\left[\eta^{t}, \tilde{\eta}_{t+1}\right]$ and $z^{t+1}$. This implies the following Kuhn-Tucker condition for the measurability constraints:

$$
\left[a_{t+1}^{z}\left(\zeta\left(z^{t+1},\left[\eta^{t}, \eta_{t+1}\right]\right) ; z^{t+1}, \eta^{t+1}\right)-a_{t+1}^{z}\left(\zeta\left(z^{t+1},\left[\eta^{t}, \tilde{\eta}_{t+1}\right]\right) ; z^{t+1},\left[\eta^{t}, \tilde{\eta}_{t+1}\right]\right)\right] \nu\left(z^{t+1}, \eta^{t+1}\right)=0
$$

for all $\left[\eta^{t}, \eta_{t+1}\right],\left[\eta^{t}, \tilde{\eta}_{t+1}\right]$ and $z^{t+1}$. Conditions (4.2,4.3) and the martingale condition (see eq. (3.7)), reproduced here,

$$
\sum_{\eta^{t+1} \succ \eta^{t}} \nu\left(z^{t+1}, \eta^{t+1}\right) \pi\left(z^{t+1}, \eta^{t+1}\right) P\left(z^{t+1}\right)=0
$$

determine the multiplier updating function: $T^{z}\left(z^{t+1}, \eta^{t+1} \mid z^{t}, \eta^{t}\right)\left(\zeta\left(z^{t}, \eta^{t}\right)\right)=\zeta\left(z^{t+1}, \eta^{t+1}\right)$. $T^{z}$ is determined by solving a simple set of simultaneous equations. Let \# denote the cardinality of a set. Using the martingale condition, note that in each node $z_{t+1}$, we have $\# Y-1$ measurability equations to be solved for $\# Y-1$ multipliers $\nu\left(z^{t+1},\left[\eta^{t}, \eta_{t+1}\right]\right)$, one for each $\eta_{t+1}$. In addition, in each node $z_{t+1}$, we have $\# Y-1$ Kuhn-Tucker conditions to be solved for $\# Y-1$ multipliers $\varphi\left(z^{t+1},\left[\eta^{t}, \eta_{t+1}\right]\right)$, one for each $\eta_{t+1}$. Finally, the law of motion for the cumulative multiplier $\zeta$ is given in (3.5).

Passive Traders For passive traders, which includes both the buy-and-hold investors and the nonparticipants as special cases, the measurability condition is given by:

$$
\frac{a_{t+1}^{j}\left(\zeta\left(z^{t+1}, \eta^{t+1}\right) ; z^{t+1}, \eta^{t+1}\right)}{R^{p}\left(z^{t}, z_{t+1}\right)}=\frac{a_{t+1}^{j}\left(\zeta\left(\left[z^{t}, \tilde{z}_{t+1}\right],\left[\eta^{t}, \tilde{\eta}_{t+1}\right]\right) ;\left[z^{t}, \tilde{z}_{t+1}\right],\left[\eta^{t}, \tilde{\eta}_{t+1}\right]\right)}{R^{p}\left(z^{t}, \tilde{z}_{t+1}\right)}, j \in\{b h, n p\}
$$

for all $\eta^{t+1},\left[\eta^{t}, \tilde{\eta}_{t+1}\right], z^{t+1}$ and $\left[z^{t}, \tilde{z}_{t+1}\right]$, the martingale condition becomes:

$$
\sum_{z^{t+1} \succ z^{t}, \eta^{t+1} \succ \eta^{t}} \nu\left(z^{t+1}, \eta^{t+1}\right) R^{p}\left(z^{t}, \tilde{z}_{t+1}\right) \pi\left(z^{t+1}, \eta^{t+1}\right) P\left(z^{t+1}\right)=0 .
$$

The updating functions for the passive traders,

$$
T^{j}\left(z^{t+1}, \eta^{t+1} \mid z^{t}, \eta^{t}\right)\left(\zeta\left(z^{t}, \eta^{t}\right)\right), \forall\left(z^{t}, \eta^{t}\right), j \in\{b h, n p\}
$$


are the solution to conditions (4.2), the Kuhn-Tucker condition associated with the measurability condition (4.4) and their martingale condition (4.5). For the buy-and-hold traders, the appropriate return is the return on diversified wealth, and for the nonparticipants it is the risk-free rate.

Definition 4.1. The updating function $T^{j}(\cdot), j \in\{z, b h, n p\}$ is a solution to a system of equations defined by:

1. the measurability conditions using the recursive expression for $a^{j}$

\section{2. the martingale conditions}

3. the solvency constraint using recursive expression for $a^{j}$

Finally, these updating functions for each of the trading technologies $T^{j}(\cdot), j \in\{z$, bh, np $\}$ determine the law of motion for the aggregate multiplier:

$$
h\left(z^{t+1}\right)=\sum_{j \in T} \int \sum_{\eta^{t+1} \succ \eta^{t}}\left\{\left[T^{j}\left(z^{t+1}, \eta^{t+1} \mid z^{t}, \eta^{t}\right)\left(\zeta\left(z^{t}, \eta^{t}\right)\right)\right]^{\frac{-1}{\alpha}} \frac{\pi\left(\eta^{t+1}, z^{t+1} \mid \eta^{t}, z^{t}\right)}{\pi\left(z^{t+1} \mid z^{t}\right)}\right\} d \Phi_{t}^{j},
$$

where $\Phi_{t}^{j}$ is the joint distribution of multipliers and endowments and $j \in\{z, b h, n p\}$.

These aggregate multiplier dynamics govern the dynamics of the SDF, and hence of risk premia and asset prices. Clearly, this defines an aggregate multiplier updating operator $\left\{h^{1}\left(z^{t}\right)\right\}=$ $T^{h}\left\{h^{0}\left(z^{t}\right)\right\}$ that maps the initial multiplier function $\left\{h\left(z^{t}\right)\right\}$ into a new aggregate multiplier function. We are looking for a fixed point of this operator.

Independence When there are no non-participants, these multiplier updating functions $T^{i}$ do not depend on the aggregate history $z^{t}$, provided that (i) the aggregate shocks are i.i.d $\left(\phi\left(z_{t+1} \mid z_{t}\right)=\right.$ $\left.\phi\left(z_{t+1}\right)\right)$ and (ii) the idiosyncratic shocks are independent of the aggregate shocks $\left(\pi\left(\eta_{t+1}, z_{t+1} \mid \eta_{t}, z_{t}\right)=\right.$ $\left.\varrho\left(\eta_{t+1} \mid \eta_{t}\right) \phi\left(z_{t+1} \mid z_{t}\right)\right)$. This result is an extension of Krueger and Lustig (2010)'s result to the case of segmented markets. As a result, the equilibrium distribution of the household multipliers (and hence the second component of the $\operatorname{SDF} h\left(z^{t+1}\right) / h\left(z^{t}\right)$ in equation (3.11)) does not depend on the realization of the aggregate shocks. In this case, the risk-free rate is lower than in the representative agent economy, but the risk premia are identical. Hence, we need non-participants to get non-trivial asset pricing effects of heterogeneity in trading technologies. As long as all households can trade a claim to diversifiable income, the lack of consumption smoothing has no bearing on risk premia, and its only effect is to lower the equilibrium risk-free rate.

We conclude this section by explaining the computational algorithm in detail. 


\subsection{Algorithm}

We forecast the growth rate of the aggregate multiplier $\left[h\left(z^{t+1}\right) / h\left(z^{t}\right)\right]$ by using a finite partition of the history of aggregate shocks $z^{t}$, with each element in the partition being assigned a distinct forecast value.

Algorithm 4.1. We construct our partition of aggregate histories $\Sigma$ by applying the following two-step procedure. $\sigma$ denotes an element of this partition.

1. Truncated Histories: In a first step, we construct a partition based upon the last $n$ aggregate shocks, which we denote by $Z^{n}$. This partition simply consists of truncated aggregate histories: $\Sigma=Z^{n}$. The number of elements in the partition is given by $\# Z^{n}$, where $\# Z$ is the number of aggregate states. We use $s \in Z^{n}$ to denote a truncated aggregate history with $n$ lags.

2. Refinement: In a second step, we further refine this partition in order to increase precision by constructing a statistic $s_{b} \in S^{b}$ that summarizes the history of aggregate shocks realized prior to $t-n, z^{t-n-1}$. The refined partition of aggregate shocks is then given by $\Sigma=Z^{n} \times S^{b}$.

The rationale for the first partition with truncated aggregate histories is straightforward. All households start off with the same multiplier at time 0. If we keep track of the history of aggregate shocks $z^{t}$ through period $t$, then obviously we know the entire distribution of multipliers at $t$, and we can compute all of its moments. Hence, the actual growth rate $\left[h\left(z^{t+1}\right) / h\left(z^{t}\right)\right]$ can be determined exactly provided that one knows the entire history of the aggregate shocks $z^{t}$. Of course, for large $t$, keeping track of the entire aggregate history becomes impractical. However, if there is an ergodic equilibrium 6 , the effect of aggregate shocks has to wear off after some time has passed 7

The additional state variable $s^{b}$ introduced in the second step soaks up residual variation in the wealth distribution that is not captured by the truncated aggregate history and hence further reduces the size of the allocation/forecast errors. We explain in detail how we implement this in section 5.2. However, its inclusion does not materially change the asset pricing results.

We define $\widehat{g}\left(\sigma, \sigma^{\prime}\right)$, where $\sigma=\left(s, s^{b}\right)$, as the forecast of the aggregate multiplier growth rate $\left[h\left(z^{t+1}\right) / h\left(z^{t}\right)\right]$, conditional on the long-run weighted average of consumption growth rate being equal to $s^{b}$, the last $n$ elements of $z^{t}$ equaling $s$, and the last $n$ elements of $z^{t+1}$ equaling $s^{\prime}$.

Algorithm 4.2. The algorithm we apply is:

1. conjecture a function $\widehat{g}_{0}\left(\sigma, \sigma^{\prime}\right)=1$.

\footnotetext{
${ }^{6}$ By ergodic equilibrium, we mean that, if we were to simulate a large number of these economies simultaneously, then the cross-sectional average of prices and allocations is well-defined and converges to a constant.

${ }^{7}$ As $n \rightarrow \infty$, the forecasts based upon this partition will converge to the actual realized growth rate. We found that we obtained reasonably accurate approximation results with $n=6$ in a calibrated version of the economy.
} 
2. solve for the equilibrium updating functions $T_{0}^{j}\left(\sigma^{\prime}, \eta^{\prime} \mid \sigma, \eta\right)(\zeta)$ for all trader groups $j \in\{z$, bh, np $\}$.

3. By simulating for a panel of $N$ households for $T$ time periods, we compute a new aggregate weight forecasting function $\widehat{g}_{1}\left(\sigma, \sigma^{\prime}\right)$.

4. We continue iterating until $\widehat{g}_{k}\left(\sigma, \sigma^{\prime}\right)$ converges.

In our approximation, we allocate consumption to households with a version of the consumption sharing rule that uses our forecast of the aggregate multiplier $\widehat{g}\left(\sigma, \sigma^{\prime}\right)$ in each aggregate node $\sigma, \zeta^{\frac{-1}{\alpha}} / \widehat{g}\left(\sigma, \sigma^{\prime}\right)$. Prices are set using the forecast as well: $m\left(\sigma^{\prime}, \sigma\right) \equiv \beta e^{-\alpha z^{\prime}} \widehat{g}\left(\sigma, \sigma^{\prime}\right)^{\alpha}$. Of course, this implies that actually allocated aggregate consumption $C^{a}$ differs from actual aggregate consumption $C$ :

$$
C^{a}\left(z^{t+1}\right)=\frac{g\left(z^{t+1}\right)}{\widehat{g}\left(\sigma, \sigma^{\prime}\right)} Y\left(z^{t+1}\right),
$$

where $g\left(z^{t+1}\right)$ is the actual growth rate of the aggregate multiplier in that aggregate node $z^{t+1}$. This equation simply follows from aggregating our consumption sharing rule across all households. When the forecast $\widehat{g}\left(\sigma, \sigma^{\prime}\right)$ deviates from the realized growth rate $g\left(z^{t+1}\right)$, this causes a gap between total allocated consumption and the aggregate endowment. Hence, the percentage forecast errors $(\log e=\log g-\log \widehat{g})$ are really allocation errors $\left(\log C^{a}-\log Y\right) 8$

With a slight abuse of notation, we use $z^{t-n} \in s^{b}$ to denote that the long-run weighted average growth rate equals $s^{b}$. We use $z^{t} \in s$ to denote that the last $n$ aggregate shocks equal $s$. The forecasts are simply the conditional sample means of the realized aggregate growth rates in each node $\left(\sigma, \sigma^{\prime}\right)$ :

$$
\log \widehat{g}\left(\sigma, \sigma^{\prime}\right)=\frac{1}{N\left(\sigma, \sigma^{\prime}\right)} \sum_{\left(z^{t-n}, z^{t}, z^{t+1}\right) \in \sigma \times \sigma^{\prime}} \log g\left(z^{t+1}\right),
$$

where $N\left(\sigma, \sigma^{\prime}\right)$ denotes the number of observations of this aggregate history in our panel. As one metric of the approximation quality, we report the standard deviation of the forecast errors:

$$
s t d\left[\log e_{t+1}\right]=s t d\left[\log \widehat{g}\left(\sigma, \sigma^{\prime}\right)-\log g\left(z^{t+1}\right)\right]
$$

Equivalently, we can also think of $\log \widehat{g}\left(\sigma, \sigma^{\prime}\right)$ as the fitted value in a regression of realized growth rates $g_{t+1}$ on dummy variables $d\left(\sigma_{t}, \sigma_{t+1}\right)$, one for each node:

$$
\log g_{t+1}=\sum_{\left(\sigma_{t}, \sigma_{t+1}\right) \in \Sigma} \log g\left(\sigma_{t}, \sigma_{t+1}\right) d\left(\sigma_{t}, \sigma_{t+1}\right)+e_{t+1}
$$

As a second metric, we also report the $R^{2}$ in the forecasting regression in equation (4.6).

\footnotetext{
${ }^{8}$ However, the household's Euler equation holds exactly in each node, given that we have set the prices and allocated consumption in each node on the basis of the forecasted aggregate multiplier, not the realized one.
} 
Advantages of our Approach Our forecasting method, which uses only the history of aggregate shocks, has several advantages. First, by using truncated aggregate histories, we avoid imposing ex ante restrictions on the relation between these histories and the growth rate of the aggregate multiplier. In the simplest case with only truncated aggregate histories in the state, we use the conditional mean, the best predictor conditional on this history, as our forecast. Second, because our forecasting relationship does not involve any equilibrium objects, we can construct the law of motion for the state variables from the primitives of our economy, before we compute an equilibrium. Third, for the same reason, the domain for the state variables can easily be determined from the primitives of the economy in our approach. Fourth, the household's state variables are given by her multiplier $\zeta$, the finite aggregate history $s$, the weighted average $s^{b}$, and her individual shock $\eta$. Since there is only a single continuous state variable in the household decision problem, the multiplier $\zeta_{t}$, we can use linear interpolation on a grid to solve the individual's problem. This solution technique is appropriate for dealing with the kink induced by the individual's solvency constraint; most of the approximation methods that are typically used to deal with continuous state variables are not. Finally, the approach that relies on equilibrium prices is more difficult to implement in our setting because it is not clear which prices should be used in the state space: all current state prices, one for each aggregate state, an average of these state prices, the price of

a claim to aggregate consumption, or the price of a claim to aggregate dividends? Furthermore, there is no reason to assume that these state prices are first-order Markov.

A detailed description of the implementation of this algorithm is available in the separate appendix. Next, we solve a calibrated version of this economy numerically, to examine the quantitative importance of heterogeneous trading opportunities for asset prices.

\section{Quantitative Results in Benchmark Model}

This section evaluates a calibrated version of the model. The benchmark model has no aggregate consumption growth predictability (IID economy). Hence, all of the dynamics are generated by the heterogeneity of trading technologies. We start with the calibration of the model in subsection 5.1. while subsection 5.2 discusses the approximation in detail. Subsection 5.3 shows that the model with heterogeneous trading opportunities manages to reconcile the low volatility of the risk free rate with the large and counter-cyclical volatility of the stochastic discount factor. Finally, subsection 5.4 gives us detailed account of how the heterogeneity in trading technologies affect the household's consumption and portfolio. 


\subsection{Calibration}

The model is calibrated to annual data. We choose a coefficient of relative risk aversion $\alpha$ of 5 and a time discount factor $\beta$ of .95 . These preference parameters allow us to match the collaterizable wealth to income ratio in the data when the tradeable or collateralizable income share $1-\gamma$ is 10\%, as estimated by Lustig, Van Nieuwerburgh, and Verdelhan (2009). Non-diversifiable income includes both labor income and entrepreneurial income, among other forms. The average ratio of household wealth to aggregate income in the US is 4.30 between 1950 and 2005. The wealth measure is total net wealth of households and non-profit organizations (Flow of Funds Tables). The implied ratio of wealth to consumption is higher (6.3) in the model's benchmark calibration, mainly because of the low risk-free rate. The households face exogenous limits on their net asset positions. The value of the household's net assets must always be greater than $-\psi$ times the value of their non-diversifiable income, where $\psi \in(0,1)$. We define the lower bound $\underline{M}\left(\eta^{t}, z^{t}\right)$ as follows:

$$
\underline{M}\left(\eta^{t}, z^{t}\right)=-\psi \sum_{\tau \geq t} \sum_{\left\{z^{\tau} \succeq z^{t}, \eta^{\tau} \succeq \eta^{t}\right\}} \gamma Y\left(z^{\tau}\right) \eta_{\tau} \frac{\pi\left(z^{\tau}, \eta^{\tau}\right) P\left(z^{\tau}, \eta^{\tau}\right)}{\pi\left(z^{t}, \eta^{t}\right) P\left(z^{t}, \eta^{t}\right)}
$$

We set the solvency constraint equal to zero: $\underline{M}=0$.

In our benchmark model, $70 \%$ of households only trade the riskless asset. The remaining $30 \%$ is split between buy-and-hold investors and active traders. This market segmentation was chosen to match the key moments of asset prices in the post-war period. In section 6, we increase the participation rate to $50 \%$. This number is more appropriate for the last two decades of the US experience. To check the plausibility of this calibration, we show that this segmentation allows for a close match of the recent asset share distribution and a better match of the recent wealth distribution in the US. This is an out-of-sample test of our calibration strategy.

In the benchmark calibration, there is no predictability in aggregate consumption growth, as in Campbell and Cochrane (1999) -we impose $\phi\left(z_{t+1} \mid z_{t}\right)=\phi\left(z_{t+1}\right)$. We refer to this as the IID economy. This is a natural benchmark case because all of the equilibrium dynamics in risk premia flow from the binding borrowing and measurability constraints, not from the dynamics of the aggregate consumption growth process itself. The other moments for aggregate consumption growth are taken from Mehra and Prescott (1985). The average consumption growth rate is $1.83 \%$. The standard deviation is $3.57 \%$. Recessions are less frequent: $27 \%$ of realizations are low aggregate consumption growth states.

In addition, we impose independence of the idiosyncratic risk from aggregate shocks on the labor income process - the following condition holds: $\pi\left(\eta_{t+1}, z_{t+1} \mid \eta_{t}, z_{t}\right)=\varrho\left(\eta_{t+1} \mid \eta_{t}\right) \phi\left(z_{t+1} \mid z_{t}\right)$. By shutting down counter-cyclical cross-sectional variance (CCV) of labor income shocks, we want to focus on the effects of concentrating aggregate risk among a small section of households, as opposed to concentrating income risk in recessions. The Markov process for $\log \eta(y, z)$ is taken 
from Storesletten, Telmer, and Yaron (2007) (see page 28). The standard deviation is .71, and the autocorrelation is 0.89 . We use a 2 -state discretization. The elements of the process for $\log \eta$ are $\{0.38,1.61\}$.

This section discusses the asset pricing implications of heterogeneous trading opportunities in the IID version of our economy. We use the IID economy as a laboratory for understanding the interaction between active and passive traders and its effect on asset prices. This interaction generates counter-cyclical state price volatility without risk-free rate volatility, unlike other heterogeneous agent models (see e.g. Chien and Lustig (2009), Alvarez and Jermann (2001), and Guvenen (2009)). The IID economy provides a natural benchmark because all investors hold the market and the risk premium is the Breeden-Lucas one if there are no non-participants. In subsection 6.4, we activate the CCV mechanism and we allow for predictability in aggregate consumption growth.

We consider two cases in the HTT (heterogeneous trading technology) economy. In the first 2 cases (reported in columns (2) and (3)), only a fraction of the market participants are active traders. In the LP (Limited Participation) economy (reported in columns (4) and (5)), all participants are active traders. Case (1) is the benchmark. The active traders make up $10 \%$ of the population. The remaining $90 \%$ is split between $20 \%$ buy-and-hold traders and $70 \%$ non-participants. We choose a low participation rate because the model's market segmentation was calibrated to match the moments of asset prices for the entire post-war period. Case (2) considers the case with only $50 \%$ non-participants, while the active traders still make up only $10 \%$ of the population. This case offers a better description of market segmentation in the last two decades. As an out-of-sample check of the model's market segmentation, we compare the implications of these choices for the wealth distribution and the asset class share distribution against the data in subsection 6.1. Finally, Case (3) and (4) (reported in columns (4) and (5)) report the results for the LP economy; all equity market participants are active traders. This is the standard case considered in the literature on limited participation. The difference between Case (1) and (3) (as well as the difference between Case (2) and Case (4)) show the effect of the heterogeneity in trading technologies. Finally, the last column reports the moments in the data.

\subsection{Approximation}

The simulation moments are generated by $T=10,000$ draws from an economy with $N=3,000$ agents. To refine the partition of aggregate histories, we construct a weighted average of aggregate shocks:

$$
b_{t}=\sum_{j=1}^{K-n} \lambda^{j} z_{t-n-j}
$$


where $K$ denotes the maximum lag considered and $\lambda>>0$ is chosen to optimize the forecasts. $b_{t-n-1}$ summarizes the history of aggregate shocks realized prior to $t-n$. The statistic $b_{t}$ is a continuous state variable on $B$; we discretize $B$ into $\# S^{b}$ states. To construct this grid, we selected cut-off values to equally divide the set of realizations into $\# S^{b}$ different bins. We chose $K=200$, and a three-part partition of $B$. Using a truncation of $n=5$, we found that a value of $\lambda=.95$ generated the largest improvement in forecast accuracy. We assign each aggregate history $z^{t}$ a spot on the grid $\Sigma=Z^{n} \times S^{b}$ using the corresponding $\left[s_{t}, b_{t}\right]$.

To assess the accuracy of the approximation method, we report the standard deviation of the $\log$ forecast errors $s t d(\log e)$, conditioning on the truncated history $s$ of length 5 , and the weighted average of consumption growth, $s^{b}$, in the last row of Table I. In the IID economy, this measure varies between $.027 \%$ and $.064 \%$. So, the forecasting/allocation errors are small. The truncated aggregate history explains most of the variation in $\log g$. As is clear from the table, the quality of the approximation does not depend on the composition of the passive trader pool. Table (V) in Section $\mathrm{B}$ of the Separate Appendix reports a second metric: the $R^{2}$ in forecasting regressions of $\log g\left(z^{\prime}, z\right)$ on $\left(s, s^{b}\right)$, as explained in equation (4.6). In Case (1) of the IID economy, these $R^{2}$ exceed .9939 for $\left(z^{\prime} z\right)$-specific state-to-state regressions and .9997 for $z^{\prime}$-specific regressions. In Case (2), these $R^{2}$ exceed .9962 and .9999 respectively. A natural question is whether we could increase the accuracy by including a small number of moments of the multiplier distribution. Section $B$ in the Separate Appendix provides a negative answer.

\subsection{Asset Pricing Results}

The asset pricing statistics were generated by drawing 10,000 realizations from the model, simulated with 3,000 agents. The left panel of Table \ reports the asset pricing results in our baseline IID experiment; the right panel reports the result for the Non-IID economy with autocorrelation in aggregate consumption growth shocks and CCV in labor income risk. We discuss the non-IID economy in section 6.4.

Equity in our model is simply a leveraged claim to diversifiable income. In the Flow of Funds, the ratio of corporate debt-to-net worth is around 0.65, suggesting a leverage parameter $\psi$ of 2 . However, Cecchetti, Lam, and Mark (1990) report that the standard deviation of the growth rate of dividends is at least 3.6 times that of aggregate consumption, suggesting that the appropriate leverage level is over 3. Following Abel (1999) and Bansal and Yaron (2004), we choose to set the leverage parameter $\psi$ to 3 in the IID economy. The returns on this security are denoted $R_{l c}$.

As a benchmark, the first column in the table also reports the corresponding numbers for the RA (representative agent) IID economy. This case is relevant, because, in the IID Economy, all of the moments of risk premia reported in column (1) are identical in the HTT economy without non-participants, regardless of the composition of the pool of participants. Hence, we need non- 
participants to get non-trivial asset pricing effects of heterogeneity in trading technologies. The composition of the other trader segments has no effect on the equity premium; the Breeden-Lucas $(R A)$ risk premium obtains and all traders hold the market portfolio. However, as soon as there is a positive fraction of non-participants, this irrelevance result disappears, and the active traders increase their exposure to market risk.

In the RA economy, the maximum Sharpe ratio is .19 and the equity risk premium $\left(E\left[R_{l c}-R_{f}\right]\right)$ is $3.08 \%$. The conditional market price of risk $\left[\sigma_{t}[m] / E_{t}[m]\right]$ is constant, because the aggregate consumption growth shocks are i.i.d. Hence, the risk premia are constant as well. Finally, the risk-free rate in the RA economy is $13 \%$ and it is also constant. As a result, there is no risk in bond returns $\left(E\left[R_{b}-R_{f}\right]=0\right)$. Hence, all of the dynamics reported below are generated by the heterogeneity in trading technologies.

In the HTT economy, the interaction between active and passive traders generates volatile state prices and a stable risk-free rate. In case (1) of the HTT economy, the maximum Sharpe ratio, $(\sigma[m] / E[m])$, is 0.44 . The risk premium on equity is $6.7 \%\left(E\left[R_{l c}-R_{f}\right]\right)$, while the standard deviation of returns $\left(\sigma\left[R_{l c}-R_{f}\right]\right)$ is $15.3 \%$. This is only slightly below the average realized excess return in post-war US data of $7.5 \%$. The risk-free rate $R_{f}$ is low (1.73\%) and essentially constant. The standard deviation of the risk-free rate is $0.10 \%$. There is also substantial time variation in expected excess returns; the standard deviation of the conditional market price of risk $S t d\left[\sigma_{t}[\mathrm{~m}] / E_{t}[\mathrm{~m}]\right]$ is $5.3 \%$. The conditional market price of risk varies between 0.35 and 0.60 . Variation in $\gamma$, the tradeable income share, only affects the average risk-free rate, but it does not affect the risk premia in this economy. If we increase $\gamma$ to 0.20 , the equity premium drops a mere 5 basis points and the maximum SR drops from 0.448 to 0.443 . However, the risk-free rate increases to 3.06 percent per annum (not shown in the table).

To illustrate the time variation in risk prices, figure 1 plots a simulated path of 100 years for the $\left\{h^{\prime} / h\right\}$ shocks to the aggregate multiplier process, the conditional risk premium on equity and the conditional market price of risk in the bottom panel. The shaded areas in the graph indicate low aggregate consumption growth states. As is clear from the top panel in Figure 1, $\left[h^{\prime} / h\right]$ is large in recessions -low aggregate consumption growth states- to induce the active traders to consume less in that state of the world, because the passive traders consume "too much" in those states. Similarly, $\left[h^{\prime} / h\right]$ needs to be small in high aggregate consumption growth states, to induce the active traders to consume more in those states. The volatility in state prices induces the small segment of active traders to reallocate consumption across aggregate states and absorb the residual aggregate risk from the non-participants. The middle panel plots the expected excess return on equity $E\left[R_{l c}-R_{f}\right]$. Clearly, the IID economy produces counter-cyclical variation in the risk premium. The underlying mechanism is shown the Net Wealth panel. The interaction between active and passive traders generates counter-cyclical variation in the conditional market price of 
risk $\left[\sigma_{t}[m] / E_{t}[m]\right]$. In high $\left[h^{\prime} / h\right]$ states, active traders realize low portfolio returns. The wealth of active traders decreases as a fraction of total wealth. This means, that in order to clear the market, the future $\left[h^{\prime} / h\right]$-shocks need to be larger (in absolute value), and this in turn increases the conditional volatility of the stochastic discount factor. As a result, the conditional market price of risk $\left[\sigma_{t}[m] / E_{t}[m]\right]$ increases after each low aggregate consumption growth realization. The driving force behind the time variation is the time-varying exposure of active traders to equity risk. We explore this in the next subsection.

[Figure 1 about here.]

\subsection{Household Portfolio Choice and Consumption}

The welfare costs of being stuck with an inferior trading technology are large. The costs are reported in percentage of lifetime consumption on the bottom of Table【. They vary from $8.6 \%$ for the buy-and-hold investor to $14.4 \%$ for non-participants. These calculations are done assuming the agent starts with the average level of wealth. In the IID economy the gains to switching are monotonically increasing in initial wealth. If we start the agents off with only $20 \%$ of average wealth, the welfare costs drop to 5.9 and $9.0 \%$ respectively.

The size of these costs is not surprising when we consider the impact on household consumption and wealth. The reason for the heterogeneity in portfolio choice is not only the heterogeneity in trading technologies, but also the presence of non-participants. In the case without nonparticipants, all households, complete, active and buy-and-hold traders would choose the same market portfolio: $25 \%$ equity and $75 \%$ bonds, given the leverage of 3, and the welfare costs of being a buy-and-hold investor are zero. This result is derived in the separate appendix; it is an extension of Krueger and Lustig (2010) to the case of segmented markets. However, in the case of non-participation, the fraction active traders invest in equity varies over time and across traders. On average, the equity share is $84 \%$ for the active trader. These fractions are highly volatile as well. The standard deviation is $21 \%$ for the active trader. Not surprisingly, the heterogeneity in portfolio choice shows up in portfolio returns. The second panel in Table I reports the average portfolio returns realized by all traders in a segment and the average wealth they accumulate. We take case (1) as our benchmark. We start with the active investors. Their investment strategy delivers an average excess return on their portfolio of $5.77 \%\left(E\left[R_{a}^{W}-R_{f}\right]\right)$ or roughly 100 basis points less than the equity premium. The buy-and-hold investor earns excess returns of around $1.68 \%$ while the non-participants realize zero excess returns. As a result, these investors do not manage to accumulate wealth. Because of his superior trading technology, the active traders accumulates 2.77 times the average wealth level $\left(E\left[W_{i} / W\right]\right)$, while the diversified trader is right at the average. Non-participants fail to accumulate wealth; on average, their holdings amount to only $76 \%$ of the average. This will severely limit the amount of self-insurance these non-participant 
households can achieve. On average, an active trader accumulates 3.43 times more wealth than the non-participant. Because the active trader invests a large fraction of his wealth in the risky asset, his wealth share is highly volatile. The coefficient of variation (ratio of standard deviation to average) for the active trader's wealth share is 51\%. However, most of this reflects aggregate rather than idiosyncratic risk. On the other hand, these coefficients of variation for the passive traders are higher, but that reflects mostly idiosyncratic risk.

On average, the active trader invests $84 \%$ in equity, but the fraction is highly volatile $(21 \%)$. Figure 1 also plots the active investor's net wealth and his equity share (share of total portfolio invested in leveraged consumption claim's). The equity share varies substantially over time, between 50 and $150 \%$. Their equity exposure tracks the variation in the conditional market price of risk and the equity premium perfectly. Since the active traders are more exposed to aggregate risk, their share of total wealth (see top panel) declines substantially after a low aggregate shock, and their "market share" declines. As a result, the conditional volatility of the aggregate multiplier shocks increases; larger shocks are needed to get the active traders to clear the markets. In response to the increase in the conditional market price of risk, the active traders increase their leverage.

This heterogeneity in portfolio choice shows up in household consumption and aggregate consumption for each trader segment as well. We report moments for household consumption as well as for average consumption aggregated across all households in a trader segment in Table II, The left panel reports the moments for consumption as a share of the aggregate endowment. The right panel reports the moments for consumption. The standard deviation of household consumption share growth can be ranked according to the trading technology, from $7.8 \%$ for the active traders to $12.4 \%$ for the non-participants. The standard self-insurance mechanism breaks down for non-participants and buy-and-hold traders; they fail to accumulate enough assets to self-insure. However, the standard deviation of the growth rate of the cross-sectional average of household consumption in a trader segment actually is highest for more sophisticated traders: the volatility is $7.55 \%$, the same number is only $3.61 \%$ for buy-and-hold traders and $2.53 \%$ for non-participants. We pointed out that constant aggregate consumption as a share of the aggregate endowment for the buy-and-hold traders trivially satisfy the aggregate measurability constraint. This turns out to be roughly what we find is the equilibrium outcome. The volatility for the aggregate group consumption shares of the buy-and-hold investors is $0.3 \%$.

Financially sophisticated households load up on aggregate consumption risk, but they are less exposed to idiosyncratic consumption risk. This is broadly in line with the data. Malloy, Moskowitz, and Vissing-Jorgensen (2007) find that the average consumption growth rate for stockholders is between 1.4 and two times as volatile as that of non-stock holders. They also find that aggregate stockholder consumption growth for the wealthiest segment (upper third) is up to 3 times as sensitive to aggregate consumption growth shocks as that of non-stock holders. The 
same number for all stockholders is only 1.4. We report the beta of group consumption growth w.r.t. aggregate consumption growth $\left.\beta\left[\Delta \log \left(C_{i}\right), \Delta \log \left(C_{a}\right)\right]\right)$ in the lower panel of Table II. In our model, this number is 1.91 for the active traders. For buy-and-hold traders, the beta is one, as predicted by the theory.

Next, we look at the correlation with the return on equity in the bottom panel. As a useful benchmark, recall the case without non-participants. Household consumption shares do not depend on aggregate shocks $z^{t}$, regardless of their trading technology, and the correlation of consumption share growth with returns is zero $\rho\left[R_{l c},\left(\Delta \log \left(\widehat{c}_{i}\right)\right]=0\right.$ for all households. In the HTT economy, because of the presence of non-participants, the correlation of consumption share growth with stock returns is highest for active traders (.498), 0 for buy-and-hold traders and -.053 for non-participants.

Of course, the active traders absorb the residual of aggregate risk created by the passive traders.

The aggregate consumption share growth of this trader segment $\left(\widehat{C}^{j}\left(z^{t}\right)=h^{j}\left(z^{t}\right) / h\left(z^{t}\right)\right)$ has a correlation of .95 with stock returns. The same correlation for buy-and-hold investors is .141, while the correlation for non-participants is -.97 .

\section{Sensitivity Analysis}

We conduct a series of additional experiments to develop an understanding of the effects of heterogeneity in trading technologies on asset prices. In the first experiment in subsection 6.1, we increase the rate of participation to match the current participation rate. The equity premium drops by 71 basis points as a result. We look at the wealth and asset share distribution implications of this calibration and compare these to current data from the Survey of Consumer Finances. In the second experiment in subsection 6.2, we replace the passive stockholders with active stockholders to decompose the results into a limited participation effect and a HTT effect. In the third experiment, we change the composition of the passive trader segment (subsection 6.3) to show that only the average equity holdings of the passive traders matters, not the actual composition. Finally, we relax the i.i.d. assumption for aggregate consumption growth in subsection 6.4.

\subsection{Increased Participation}

Case (2) (reported in column (3) of Table I) reports the effect on asset prices in the HTT economy when participation increases to $50 \%$. This is also closer to the actual participation rate in the US economy in the last decade. Active traders still make up $10 \%$ of the population. The market price of risk drops from 0.45 to 0.41 and the equity premium drops by 71 basis points to $6.01 \%$. Hence, our model predicts a substantial decrease in the risk premium as a result of recent increases in participation, consistent with the evidence reported in Fama and French (2002) and Jagannathan, McGrattan, and Scherbina (2000). However, the equity premium is still almost 300 basis points 
larger than in the representative agent economy. In addition, the increased participation reduces the volatility of the market price of risk from 5.3 to $4.2 \%$.

Implications for the Wealth Distribution Table III compares the wealth distribution implications of this version of the calibrated model to wealth data from the 2004 Survey of Consumer Finances. We introduce permanent income differences to match the joint income distribution and wealth distribution in the data, while keeping the fraction of human wealth in each trader segment constant. This way, the asset pricing implications of the model are preserved because of the homogeneity that is built into the model. In the twisted calibration, the active traders make up $5 \%$ of the population and hold $10 \%$ of human wealth. The buy-and-hold traders hold $40 \%$ of human wealth but make up $35 \%$ of the population. Finally, the non-participants hold $50 \%$ of wealth but make up $60 \%$ of the population. The first two columns display the model's income distribution vs that in the data at different percentiles of the wealth distribution. We obtain a close match of the income distribution in the data.

We consider two benchmark models. The IC (Incomplete Markets) model has no heterogeneity in trading technologies. This is a standard incomplete markets model. All agents are buy-and-hold traders who hold the market. Note that this is the optimal portfolio choice given that there are no non-participants. We also consider a LP (limited participation) version of the model with $50 \%$ of wealth held by active traders and $50 \%$ of wealth held by non-participants 9 However, they make up $35 \%$ and $65 \%$ of the population respectively.

The top panel in Table III reports the summary statistics for the IC model and the HTT model. We contrast the model's predictions with the same statistics from the 2004 SCF for US households. The Gini coefficient in the data is .793 (.697 for total assets, source: SCF, 2004). Our model produces a Gini coefficient of .56. The model without heterogeneous trading opportunities produces a Gini coefficient of .47. So, the heterogeneity in trading opportunities bridges half of the gap with the data, by producing fatter tails and a more skewed distribution. The skewness of the wealth distribution increases from .9 to 2.81 (compared to 3.6 in the data) while the kurtosis increases from 3.2 to 14.7 . (compared to 15.9 in the data).

The $75 / 25$ ratio increases to 7.51 from 4.78 while the $85 / 25$ ratio increases to 9.81 from 6.39 . The 90/10 ratio increases to 195 from 82. However, the HTT model still falls well short of the data. The poor households accumulate too much wealth in the model compared to the data. However, the model does quite well in matching the right tail of the wealth distribution in the data.

Implications for the Asset Share Distribution Finally, we turn to the asset class share distribution, and we check whether our model can replicate the distribution of equity shares in

\footnotetext{
${ }^{9}$ This corresponds to case (4) in Table
} 
the data. We also consider the LP (limited participation) version of our economy with $50 \%$ nonparticipants and $50 \%$ active traders. Table portfolio) at different percentiles of the wealth distribution in the model and the data. In the data, we rank households in terms of net worth and we backed out their equity holding as a fraction of net wealth. We include private businesses in equity. In the IC model, all households hold the market portfolio. Hence, the IC model over-predicts the equity shares for all households below the $80 \%$ and under-predicts for the wealthier households. The LP model model tends to over-predict equity shares below the 95-th percentile, and it under-predicts for the higher percentiles. Clearly, the HTT model delivers an improvement of the match with the equity share distribution in the data compared to existing models.

\subsection{Limited Participation}

To disentangle the effects of heterogeneity in trading technologies from the effects of limited participation, Cases (3) and (4) report the same moments of asset prices that obtain when all stock market participants are active traders. Hence, we eliminate the heterogeneity in trading technologies among market participants altogether. This is the standard case considered in the literature on limited participation (see e.g. Gomes and Michaelides (2008)). By comparing case (1) and (3) ((2) and (4) respectively), we get a precise measure of the impact of the heterogeneity in trading technologies. The impact is substantial. In case (1), the equity premium drops 197 basis points when we replace the $20 \%$ buy-and-hold traders with active traders. In other words $54 \%$ of the increase in the equity premium (relative to the RA case) is due to the heterogeneity in trading technologies, not limited participation. The market price of risk decreases from 0.45 to 0.33 and its volatility drops from $5.3 \%$ to $2.0 \%$. In case (2), the drop in the equity risk premium is 228 basis points (compare to case (4)). The equity premium is only 64 basis points higher than the RA case. In this case, the heterogeneity accounts for $78 \%$ of the increase in the equity premium.

\subsection{Composition of the Passive Trader Pool}

Clearly, the composition of the pool of participants (active v.s buy-and-hold investors) matters for the size of the risk premium. However, the exact composition of the pool of passive traders is much less important. To make this point, Table IV fixes the average equity holdings of all passive traders at the level in the benchmark model reported in case (1) in Table I but it changes the composition of the passive trader pool. This experiment is labeled ' $1 \mathrm{x}$ '. In this benchmark case, the average passive trader holds $5.56 \%$ in equity: $77 \%$ of passive traders (non-participants) hold no equity while $23 \%$ (buy-and-hold traders) hold $25 \%$ equity. In the IID economy (left panel in IV), changes in the composition of the pool have only small effects on risk premia. What matters 
for risk premia is the average equity holdings of the passive traders. The equity risk premium is roughly constant across Case (a)-Case (c).

We also double the level of equity holdings of the passive traders. This experiment is labeled ' $2 \mathrm{x}$ ' The equity risk premium declines from $6.71 \%$ in the ' $1 \mathrm{x}$ ' case to $5.53 \%$ in the ' $2 \mathrm{x}$ ' case. However, interestingly, the volatility of risk premia seems largely unaffected by the increase in average equity participation. In fact, in case (a), the benchmark case, the volatility of the market price of risk increases from 5.3\% to 5.7\%. Passive traders's demand for risky assets is inelastic with respect to variation in state prices. Hence, the required variation in the size of state price adjustments to clear asset markets do not decline as equity holdings increase.

\subsection{Non-IID Economy}

Finally, in another robustness check, we relax the i.i.d. assumption for aggregate consumption growth and we allow for counter-cyclical cross-sectional variation in labor income. The aggregate consumption growth dynamics match those in Mehra and Prescott (1985): we set the first-order autocorrelation to -.14 . The other moments of aggregate consumption growth are unchanged. In addition, we allow for a concentration for income risk in recessions, as suggested by Mankiw (1986), Constantinides and Duffie (1996) and documented in the data by Storesletten, Telmer, and Yaron (2004). To determine the idiosyncratic shocks in this case, we follow Alvarez and Jermann (2001)

and impose that $\frac{s t d\left(\ln \eta^{\prime} \mid z^{\prime}=R\right)}{s t d\left(\ln \eta^{\prime} \mid z^{\prime}=E\right)}=1.88$. We reduce the leverage parameter $\psi$ from 3 to 2 in this case, because the interest rate variation imputes more volatility to dividend growth and returns. This also implies that the buy-and-hold investor now invests $33 \%$ in equities and $66 \%$ in the risk-free asset.

Asset Pricing Results The asset pricing results are reported in the right panel of Table I. In column (1), we report the results for the RA economy. The negative autocorrelation in aggregate consumption growth imputes volatility to the risk-free rate of about $3 \%$ per annum. However, we adjusted the leverage parameter from 3 to 2 , to target the volatility of stock excess returns of about $16 \%$ per annum in the data; without this adjustment, the volatility implied by the Non-IID model is $21.5 \%$. In the benchmark case (Case (1)), the maximum Sharpe ratio increases from 0.45 to 0.47 per annum. The actual Sharpe ratio on equity is 0.45 . More importantly, the negative autocorrelation makes longer bonds risky again, and thus delivers an upward sloping real yield curve. This is not shown in the Table.

Approximation The quality of the approximation does depend on the properties of aggregate consumption growth and labor income. In the non-IID economy, the size the approximation error statistic $\operatorname{std}(\log e)$ varies between $0.05 \%$ and $0.095 \%$, about double the size of the errors in the IID 
economy, mainly because the volatility of the shocks to $g$ more than doubles.

\section{Conclusion}

To solve a dynamic incomplete markets model populated by agents with different trading technologies, we show that the same consumption sharing rule, which relates the household's multiplier, its state variable, to its consumption, applies to all households, regardless of their trading technology, even though the multiplier's dynamics are different for different trading technologies. This allows to derive an expression for state prices as a function of the aggregate multiplier, which is one specific moment of the distribution of multipliers across households and trading technologies. To solve for the equilibrium allocations and market-clearing prices, we simply need to forecast the growth rate of this aggregate multiplier in each aggregate state of the world. In a calibrated version of the model, we show that a truncated version of the history of aggregate shocks does well in forecasting this growth rate.

In the quantitative section of the paper, we calibrate a model with heterogeneity in trading technologies to match the historical average of the risk-free rate and the equity premium. The heterogeneity in trading opportunities that we introduce brings the standard model much closer to matching the asset class share and wealth distribution in the data. The passive traders in our model accumulate much less wealth than the active traders, even though they have identical preferences,

simply because the latter are compensated for bearing the residual aggregate risk created by the non-participants. Hence, it is imperative to study the wealth and asset share distribution in a model that generates large and volatile risk premia. However, the heterogeneity in trading opportunities cannot fully account for the lack of wealth accumulation among US households that are part of the middle class.

\section{References}

Abel, A. B. (1999): "Risk Premia and Term Premia in General Equilibrium," Journal of Monetary Economics, 43, 3-33.

Aiyagari, S. R., A. Marcet, T. J. Sargent, and J. Seppala (2002): "Optimal Taxation Without State-Contingent Debt," Journal of Political Economy, 110(6), 1220-1254.

Alvarez, F., and U. Jermann (2001): "Quantitative Asset Pricing Implications of Endogenous Solvency Constraints," Review of Financial Studies, 14, 1117-1152.

Bansal, R., And A. Yaron (2004): "Risks for the Long-Run: A Potential Resolution of Asset Pricing Puzzles," Journal of Finance, 59(4), 1481-1509. 
Basak, S., And D. Cuoco (1998): "An Equilibrium Model with Restricted Stock Market Participation," Review of Financial Studies, Vol. 11(2), pp. 309-341.

Calvet, L. E., J. Y. Campbell, and P. Sodini (2007): "Down or Out: Assessing The Welfare Costs of Household Investment Mistakes.," Journal of Political Economy, 115(5), 707-747.

Campbell, J. Y. (2006): "Household Finance," Journal of Finance, LXI(4), 1553-1607.

Campbell, J. Y., and J. H. Cochrane (1999): "By Force of Habit: A Consumption-Based Explanation of Aggregate Stock Market Behavior," Journal of Political Economy, 107(2), 205251.

Cecchetti, S. G., P.-S. Lam, and N. C. Mark (1990): "Mean Reversion in Equilibrium Asset Prices," American Economic Review, Vol. 80, No. 3, 398-418.

Chien, Y.-L., And H. Lustig (2009): "The Market Price of Aggregate Risk and the Wealth Distribution," Review of Financial Studies, Advance Access published online on October 8, 2009, 1-55.

Constantinides, G. M., And D. Duffie (1996): "Asset Pricing with Heterogeneous Consumers," Journal of Political Economy, 104, 219-240.

Cuoco, D., And H. He (2001): "Dynamic Equilibrium in Infinite Dimensional Economies with Incomplete Financial Markets," Annals of Economics and Finance, 2, 265-296.

Dumas, B. (1989): "Two-Person Dynamic Equilibrium in the Capital Markets," Review of Financial Studies, 2(2), 157-188.

Fama, E. F., And K. R. French (2002): "The Equity Premium," Journal of Finance, 57(2), 637-659.

Gomes, F., And A. Michaelides (2008): "Asset Pricing with Limited Risk Sharing and Heterogeneous Agents," Review of Financial Studies, 21(1), 415-448.

Guvenen, F. (2009): "A Parsimonious Macroeconomic Model for Asset Pricing," Econometrica, $77(6), 1711-1750$.

Hellwig, C., And G. Lorenzoni (2009): "Bubbles and Self-Enforcing Debt," Econometrica, 77, 1137-1164.

Jagannathan, R., E. R. McGrattan, and A. Scherbina (2000): "The Declining U.S. Equity Premium," Federal Reserve Bank of Minneapolis Quarterly Review, 24(4), 3-19. 
Kehoe, P. J., And F. Perri (2002): "International Business Cycles with Endogenous Incomplete Markets," Econometrica, 70(3), 907-928.

Krueger, D., And H. Lustig (2010): "When is Market Incompleteness Irrelevant for the Price of Aggregate Risk (and when is it not)?," Journal of Economic Theory, 145(1), 1-41.

Krusell, P., And A. Smith (1997): "Income and Wealth Heterogeity, Portfolio Choice, and Equilibrium Asset Returns," Macroeconomic Dynamics, 1, 387-422.

(1998): "Income and Wealth Heterogeneity in the Macroeconomy," Journal of Political Economy, 6, 867-896.

Lustig, H., and S. V. Nieuwerburgh (2005): "Housing Collateral, Consumption Insurance and Risk Premia: an Empirical Perspective," Journal of Finance, 60(3), 1167-1219.

Lustig, H., C. Sleet, And S. Yeltekin (2007): "Fiscal hedging with nominal assets," Journal of Monetary Economics, 55(4), 710-727.

Lustig, H., S. Van Nieuwerburgh, and A. Verdelhan (2009): "The Wealth-Consumption Ratio," Working Paper.

Malloy, C., T. Moskowitz, and A. Vissing-Jorgensen (2007): "Long-Run Stockholder Consumption Risk and Asset Returns," .

Mankiw, G. N. (1986): "The Equity Premium and the Concentration of Aggregate Shocks," Journal of Financial Economics, 17, 211-219.

Marcet, A., and R. Marimon (1999): "Recursive Contracts," Working Paper Universitat Pompeu Fabra.

Mehra, And E. Prescott (1985): "The Equity Premium: A Puzzle.," Journal of Monetary Economics, 15(2), 145-161.

Parker, J. A., And A. Vissing-Jorgensen (2009): "Who Bears Aggregate Fluctuations and How?," NBER Working Paper No. 14665.

Saito, M. (1996): "Limited Participation and Asset Prices," Working Paper University of British Columbia.

Storesletten, K., C. Telmer, and A. Yaron (2004): "Cyclical Dynamics in Idiosyncratic Labor-Market Risk," Journal of Political Economy, 112, 695-717. 
(2007): "Asset pricing with idiosyncratic risk and overlapping generations," Review of Economic Dynamics, 10(4), 519-548.

Vissing-Jorgensen, A. (2002): "Limited Asset market Participation and Elasticity of Intertemporal Substitution," The Journal of Political Economy, 110(4), 825-853.

\section{A Proofs}

- Proof of Corollary 3.1 .

Proof. We know that $E\left\{\zeta\left(z^{t+1}, \eta^{t+1}\right) \mid z^{t+1}\right\} \leq \zeta\left(z^{t}, \eta^{t}\right)$. This implies that

$$
E\left\{\zeta^{-1 / \alpha}\left(z^{t+1}, \eta^{t+1}\right) \mid z^{t+1}\right\} \geq E\left\{\zeta\left(z^{t+1}, \eta^{t+1}\right) \mid z^{t+1}\right\}^{-1 / \alpha}=\zeta\left(z^{t}, \eta^{t}\right)^{-1 / \alpha}
$$

Assume $h\left(z^{t+1}\right) \leq h\left(z^{t}\right)$. Then the risk-sharing rule in (3.10) implies the unconstrained active trader's consumption share increases over time.

- Proof of proposition 3.1 .

Proof. We have shown that, if interest rates are high enough (i.e. if the present value of the aggregate endowment is finite), any feasible allocation in the sequential economy satisfies the static budget constraints, using the recursive definition of state prices, as well as the static version of the solvency and the measurability constraints. Hence, the sequential equilibrium allocation is feasible in the static economy. It is sufficient to define Lagrangian multipliers for the static budget constraints, solvency constraints and measurability constraints, and verify that these are a saddle. The initial multiplier on the static budget constraint $\chi$ are identical for all households. Subsequently, the cumulative multipliers in each node $\left(z^{t}, \eta^{t}\right)$ can be constructed recursively from the prices

$$
\beta^{t} u^{\prime}\left(c\left(z^{t}, \eta^{t}\right)\right)=P\left(z^{t}\right) \zeta\left(z^{t}, \eta^{t}\right)
$$

These multipliers are non-negative because state prices are. The saddle point property fol- 
lows. We define the Lagrangian as follows:

$$
\left.\begin{array}{r}
L\left(\{\bar{c}\},\left\{\bar{a}_{-1}\right\},\{\bar{\gamma}\},\{\bar{\nu}\},\{\bar{\varphi}\}\right)=\sum_{t=1}^{\infty} \beta^{t} \sum_{\left(z^{t}, \eta^{t}\right)} u\left(c\left(z^{t}, \eta^{t}\right)\right) \pi\left(z^{t}, \eta^{t}\right) \\
+\bar{\chi}\left\{\sum_{t \geq 1} \sum_{\left(z^{t}, \eta^{t}\right)} \widetilde{P}\left(z^{t}, \eta^{t}\right)\left[\gamma Y\left(z^{t}\right) \eta_{t}-\bar{c}\left(z^{t}, \eta^{t}\right)\right]+a_{-1}\left(z^{0}\right)\right\}
\end{array}\right\}
$$

First, note that the $\zeta$ we constructed minimizes $L(\{\bar{c}\},\{\bar{\gamma}\},\{\bar{\nu}\},\{\bar{\varphi}\})$ for the sequential equilibrium allocations $\{c\}$ because the multipliers are zero when the constraints do not bind, by construction from the sequential equilibrium allocations. Define

$$
L(\{\bar{c}\},\{\zeta\})=\sum_{t=1}^{\infty} \beta^{t} \sum_{\left(z^{t}, \eta^{t}\right)} u\left(\bar{c}\left(z^{t}, \eta^{t}\right)\right) \pi\left(z^{t}, \eta^{t}\right)-\sum_{t \geq 1} \sum_{\left(z^{t}, \eta^{t}\right)} \widetilde{P}\left(z^{t}, \eta^{t}\right)\left[\zeta\left(z^{t}, \eta^{t}\right) \bar{c}\left(z^{t}, \eta^{t}\right)\right]
$$

where we have left out the rest of the Lagrangian that does not depend on $\{\bar{c}\}$. To show that this is a saddle point, it only remains to show that the sequential equilibrium allocations $\{c\}$ maximize the Lagrangian $L(\{\bar{c}\},\{\zeta\}: L(\{\bar{c}\},\{\zeta\}) \leq L(\{c\},\{\zeta\})$, which follows directly from the first order condition in (A.1) and from the fact that by concavity and differentiability we have that $u(\bar{c}) \leq u(c)+u^{\prime}(c)[\bar{c}-c]$. To derive the saddle point result, it is sufficient to substitute the right hand side of this last equation into the Lagrangian.

- Proof of proposition 3.3 .

Proof. First, since the measurability constraints are satisfied for the individual household's savings function, they also need to be satisfied for the aggregate savings function. So by the LLN:

$$
\frac{A^{b h}\left(z^{t+1}\right)}{\left[(1-\gamma) Y\left(z^{t+1}\right)+\omega\left(z^{t+1}\right)\right]}=\frac{A^{b h}\left(z^{t}, \tilde{z}_{t+1}\right)}{\left[(1-\gamma) Y\left(\left[z^{t}, \tilde{z}_{t+1}\right]\right)+\omega\left(\left[z^{t}, \tilde{z}_{t+1}\right]\right)\right]}
$$

where we have used the fact that the denominator is measurable w.r.t. $z^{t}$. Note that $\sum_{k} A^{k}\left(z^{t+1}\right)=-\left[(1-\gamma) Y\left(z^{t}, \tilde{z}_{t+1}\right)+\omega\left(z^{t}, \tilde{z}_{t+1}\right)\right]$. Hence the ratio $A_{a}^{b h}\left(z^{t+1}\right) / \sum_{k} A^{k}\left(z^{t+1}\right)=$ $\kappa\left(z^{t}\right)$ cannot not depend on $z_{t}$, because of the measurability condition. 
Table I: Moments of Asset Prices and Composition of Market Participant Pool

\begin{tabular}{|c|c|c|c|c|c|c|c|c|c|c|c|}
\hline & \multicolumn{5}{|c|}{ Benchmark IID Economy } & \multicolumn{5}{|c|}{ Non-IID Economy with CCV } & \multirow[b]{2}{*}{ Data } \\
\hline & RA Economy & \multicolumn{2}{|c|}{ HTT Economy } & \multicolumn{2}{|c|}{ LP Economy } & RA Economy & \multicolumn{2}{|c|}{ HTT Economy } & \multicolumn{2}{|c|}{ LP Economy } & \\
\hline & & Case (1) & Case (2) & Case (3) & Case (4) & & Case (1) & Case (2) & Case (3) & Case (4) & \\
\hline active & & $10 \%$ & $10 \%$ & $30 \%$ & $50 \%$ & & $10 \%$ & $10 \%$ & $30 \%$ & $50 \%$ & \\
\hline buy-and-hold & & $20 \%$ & $40 \%$ & $0 \%$ & $0 \%$ & & $20 \%$ & $40 \%$ & $0 \%$ & $0 \%$ & \\
\hline \multirow[t]{2}{*}{ non-part } & & $70 \%$ & $50 \%$ & $70 \%$ & $50 \%$ & & $70 \%$ & $50 \%$ & $70 \%$ & $50 \%$ & \\
\hline & \multicolumn{5}{|c|}{ Asset Prices $\psi=3$} & \multicolumn{5}{|c|}{ Asset Prices $\psi=2$} & \\
\hline$E\left[R_{f}\right]$ & 12.96 & 1.728 & 1.919 & 2.232 & 2.496 & 13.04 & 1.315 & 1.579 & 1.895 & 2.277 & 1.049 \\
\hline$\sigma\left[R_{f}\right]$ & 0.000 & 0.102 & 0.092 & 0.074 & 0.042 & 3.144 & 3.085 & 3.060 & 3.026 & 2.952 & 1.560 \\
\hline$\sigma[m] / E[m]$ & 0.193 & 0.448 & 0.409 & 0.326 & 0.259 & 0.193 & 0.471 & 0.427 & 0.354 & 0.280 & \\
\hline $\operatorname{Std}\left[\sigma_{t}[m] / E_{t}[m]\right]$ & 0.000 & 0.053 & 0.042 & 0.020 & 0.008 & 0.011 & 0.061 & 0.047 & 0.029 & 0.018 & \\
\hline$E\left[R_{l c}-R_{f}\right]$ & 3.081 & 6.714 & 6.008 & 4.740 & 3.725 & 3.325 & 7.376 & 6.613 & 5.516 & 4.361 & 7.531 \\
\hline$\sigma\left[R_{l c}-R_{f}\right]$ & 15.94 & 15.297 & 14.881 & 14.634 & 14.459 & 17.282 & 16.106 & 15.787 & 15.768 & 15.686 & 16.94 \\
\hline$E\left[R_{l c}-R_{f}\right] / \sigma\left[R_{l c}-R_{f}\right]$ & 0.193 & 0.439 & 0.404 & 0.324 & 0.258 & 0.192 & 0.458 & 0.419 & 0.350 & 0.278 & 0.444 \\
\hline \multirow[t]{2}{*}{$E\left[W^{\text {Coll }} / C\right]$} & 0.855 & 6.473 & 6.404 & 6.400 & 6.365 & 0.835 & 5.586 & 5.539 & 5.688 & 5.691 & 3.870 \\
\hline & & \multicolumn{4}{|c|}{ Portfolio Returns and Wealth } & & \multicolumn{4}{|c|}{ Portfolio Returns and Wealth } & \\
\hline$E\left[R_{z}^{W}-R_{f}\right]$ & & 5.768 & 4.935 & 3.081 & 1.703 & & 6.590 & 5.630 & 3.949 & 2.301 & \\
\hline$E\left[R_{b h}^{W}-R_{f}\right]$ & & 1.681 & 1.504 & -- & -- & & 2.450 & 2.196 & -- & -- & \\
\hline$E\left[R_{n p}^{W}-R_{f}\right]$ & & 0 & & 0 & 0 & & 0 & 0 & 0 & 0 & \\
\hline$E\left[W_{z} / W\right]$ & & 2.766 & 2.147 & 1.413 & 1.140 & & 3.117 & 2.328 & 1.532 & 1.175 & \\
\hline$E\left[W_{b h} / W\right]$ & & 0.958 & 0.976 & -- & -- & & 0.953 & 0.982 & -- & -- & \\
\hline \multirow[t]{2}{*}{$E\left[W_{n p} / W\right]$} & & 0.761 & 0.791 & 0.823 & 0.859 & & 0.711 & 0.749 & 0.772 & 0.825 & \\
\hline & & \multicolumn{4}{|c|}{ Welfare Costs } & & \multicolumn{4}{|c|}{ Welfare Costs } & \\
\hline buy-and-hold & & 8.6445 & 6.2271 & -- & -- & & 6.5383 & 4.5080 & -- & -- & \\
\hline \multirow[t]{2}{*}{ non-part } & & 14.363 & 10.979 & 5.3751 & 2.3705 & & 14.668 & 11.257 & 6.6986 & 3.4630 & \\
\hline & & \multicolumn{4}{|c|}{ Approximation } & & \multicolumn{4}{|c|}{ Approximation } & \\
\hline$s t d[\log (e)](\%)$ & & 0.0645 & 0.0414 & 0.0465 & 0.0279 & & 0.0952 & 0.0588 & 0.0782 & 0.0502 & \\
\hline
\end{tabular}

Notes: Parameters setting: $\gamma=5, \beta=0.95$, collateralized share of income is 0.1 . The simulation moments are generated by 10,000 draws from an economy with 3,000 agents. The IID Economy panel reports results for the Benchmark calibration of idiosyncratic shocks and i.i.d. calibration of aggregate shocks; the leverage parameter $\psi$ is 3 in the IID economy. The non-IID Economy panel reports results for the STY calibration of idiosyncratic shocks and MP calibration of aggregate shocks; the leverage parameter $\psi$ is 2 in the non-IID economy. The table reports the moments of asset prices for the RA (Representative Agent) economy, for the HTT (Heterogeneous Trading Technology) economy, the LP (limited participation) economy and for the data. We use post-war US annual data for 1946-2005. The market return is the CRSP value weighted return for NYSE/NASDAQ/AMEX. We use the Fama risk-free rate series from CRSP (average 3-month yield). To compute the standard deviation of the risk-free rate, we compute the annualized standard deviation of the ex post real monthly risk-free rate. The welfare cost is the percentage of consumption that the non-participant (buy-and-hold investor) is willing to give up to become an active trader. The last row $(s t d[\log (e)](\%))$ reports the standard deviation of the allocation error in percentage points. 
Table II: Moments of Household and Group Consumption in IID Economy for Case (1)

\begin{tabular}{|c|c|c|c|c|c|c|c|}
\hline \multicolumn{4}{|c|}{ Panel I: moments of consumption share growth } & \multicolumn{4}{|c|}{ Panel II: moments of consumption growth } \\
\hline \multicolumn{2}{|c|}{ Household } & \multicolumn{2}{|c|}{ Group Average } & \multicolumn{2}{|c|}{ Household } & \multicolumn{2}{|l|}{ Group Average } \\
\hline$\sigma\left[\Delta \log \left(\widehat{c}_{z}\right)\right]$ & 7.802 & $\sigma\left[\Delta \log \left(\widehat{C}_{z}\right)\right]$ & 4.111 & $\sigma\left[\Delta \log \left(c_{z}\right)\right]$ & 10.127 & $\sigma\left[\Delta \log \left(C_{z}\right)\right]$ & 7.547 \\
\hline$\sigma\left[\Delta \log \left(\widehat{c}_{b h}\right)\right]$ & 11.344 & $\sigma\left[\Delta \log \left(\widehat{C}_{b h}\right)\right]$ & 0.304 & $\sigma\left[\Delta \log \left(c_{b h}\right)\right]$ & 12.112 & $\sigma\left[\Delta \log \left(C_{d i v}\right)\right]$ & 3.612 \\
\hline$\sigma\left[\Delta \log \left(\widehat{c}_{n p}\right)\right]$ & 12.427 & $\sigma\left[\Delta \log \left(\widehat{C}_{n p}\right)\right]$ & 1.081 & $\sigma\left[\Delta \log \left(c_{n p}\right)\right]$ & 12.908 & $\sigma\left[\Delta \log \left(C_{n p}\right)\right]$ & 2.534 \\
\hline$\rho\left[R_{l c},\left(\Delta \log \left(\widehat{c}_{z}\right)\right]\right.$ & 0.498 & $\rho\left[R_{l c}, \Delta \log \left(\widehat{C}_{z}\right)\right]$ & 0.948 & $\rho\left[R_{l c},\left(\Delta \log \left(c_{z}\right)\right]\right.$ & 0.726 & $\beta\left[\Delta \log \left(C_{z}\right), \Delta \log \left(C_{a}\right)\right]$ & 1.912 \\
\hline$\rho\left[R_{l c},\left(\Delta \log \left(\widehat{c}_{b h}\right)\right]\right.$ & 0.003 & $\rho\left[R_{l c}, \Delta \log \left(\widehat{C}_{b h}\right)\right]$ & 0.141 & $\rho\left[R_{l c},\left(\Delta \log \left(c_{b h}\right)\right]\right.$ & 0.198 & $\beta\left[\Delta \log \left(C_{d i v}\right), \Delta \log \left(C_{a}\right)\right]$ & 1.007 \\
\hline$\rho\left[R_{l c},\left(\Delta \log \left(\widehat{c}_{n p}\right)\right]\right.$ & -0.053 & $\rho\left[R_{l c}, \Delta \log \left(\widehat{C}_{n p}\right)\right]$ & -0.974 & $\rho\left[R_{l c},\left(\Delta \log \left(c_{n p}\right)\right]\right.$ & 0.143 & $\beta\left[\Delta \log \left(C_{n p}\right), \Delta \log \left(C_{a}\right)\right]$ & 0.761 \\
\hline
\end{tabular}

Notes: Parameters setting: $\gamma=5, \beta=0.95$, collateralized share of income is 0.1 . The simulation moments are generated by 10,000 draws from an economy with 3,000 agents. Benchmark calibration of idiosyncratic shocks and IID calibration of aggregate shocks. The HTT model has $10 \%$ active traders, $20 \%$ buy-and-hold traders and $70 \%$ non-participants. This is Case (1) in Table \ The first panel reports the moments for household consumption share growth and the growth rate of the cross-sectional average of household consumption in each trader segment. The second panel reports the moments for household consumption growth and for the growth rates of the cross-sectional average of household consumption in each trader segment. Hatted variables denote shares of the aggregate endowment. 
Table III: Household Wealth Distribution in IID Economy for Case (2)

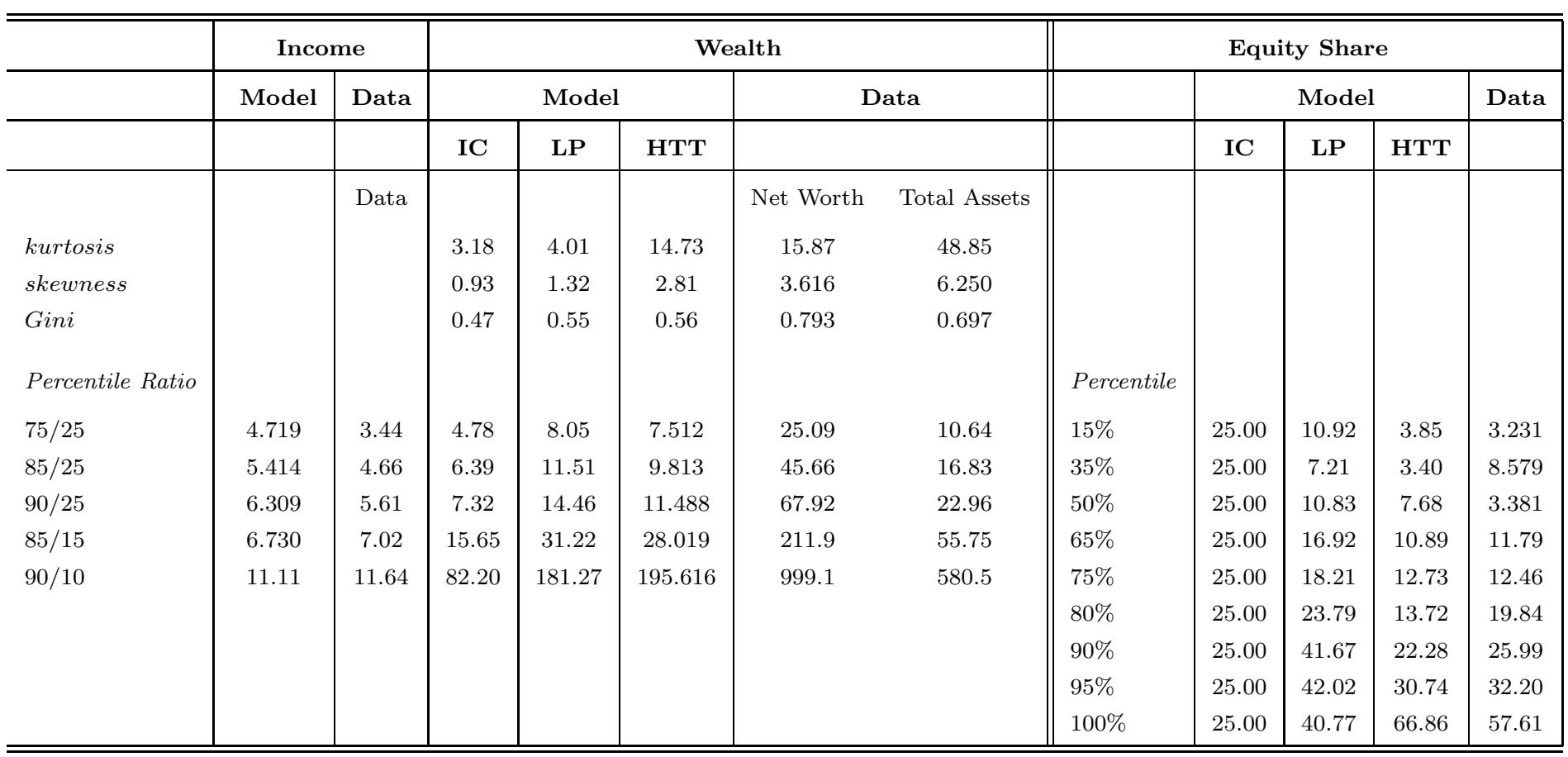

Notes: Parameters setting: $\gamma=5, \beta=0.95$, collateralized share of income is 0.1 . The simulation moments are generated by 10,000 draws from an economy with 3,000 agents Benchmark calibration of idiosyncratic shocks and aggregate shocks. The wealth data are from the 2004 SCF. The HTT model has $10 \%$ active traders, $40 \%$ buy-and-hold traders and $50 \%$ non-participants. The IC has $100 \%$ buy-and-hold traders. The LP model has $50 \%$ non-participants and $50 \%$ active traders. The income data are from the 2004 SCF. The wealth data are from the $2004 \mathrm{SCF}$. The equity share reported is the share of equity (including private business) as a fraction of net worth. The data are from the $2004 \mathrm{SCF}$. 
Table IV: Moments of Asset Prices and the Composition of the Passive Trader Pool

\begin{tabular}{|c|c|c|c|c|c|c|c|c|c|c|c|c|}
\hline & \multicolumn{6}{|c|}{ Benchmark IID Economy } & \multicolumn{6}{|c|}{ Non-IID Economy with CCV } \\
\hline & \multicolumn{3}{|c|}{$1 \mathrm{x}$} & \multicolumn{3}{|c|}{$2 \mathrm{x}$} & \multicolumn{3}{|c|}{$1 \mathrm{x}$} & \multicolumn{3}{|c|}{$2 \mathrm{x}$} \\
\hline & Case (a) & Case (b) & Case (c) & Case (d) & Case (e) & Case (f) & Case (a) & Case (b) & Case (c) & Case (d) & Case (e) & Case $(f)$ \\
\hline buy-and-hold & $20 \%$ & $40 \%$ & $60 \%$ & $20 \%$ & $40 \%$ & $60 \%$ & $20 \%$ & $40 \%$ & $60 \%$ & $20 \%$ & $40 \%$ & $60 \%$ \\
\hline non-participant & $70 \%$ & $50 \%$ & $30 \%$ & $70 \%$ & $50 \%$ & $30 \%$ & $70 \%$ & $50 \%$ & $30 \%$ & $70 \%$ & $50 \%$ & $30 \%$ \\
\hline$E\left[R_{f}\right]$ & 1.728 & 1.700 & 1.692 & 2.058 & 1.937 & 1.900 & 1.315 & 1.274 & 1.264 & 1.916 & 1.577 & 1.515 \\
\hline$S t d\left[\sigma_{t}[m] / E_{t}[m]\right]$ & 0.053 & 0.052 & 0.052 & 0.057 & 0.044 & 0.042 & 0.061 & 0.060 & 0.060 & 0.084 & 0.048 & 0.046 \\
\hline$E\left[R_{l c}-R_{f}\right]$ & 6.714 & 6.794 & 6.853 & 5.530 & 5.982 & 6.104 & 7.376 & 7.479 & 7.575 & 5.626 & 6.691 & 6.838 \\
\hline$\sigma\left[R_{l c}-R_{f}\right]$ & 15.297 & 15.336 & 15.426 & 15.039 & 14.975 & 14.991 & 16.105 & 16.138 & 16.273 & 16.278 & 15.974 & 15.935 \\
\hline$E\left[R_{l c}-R_{f}\right] / \sigma\left[R_{l c}-R_{f}\right]$ & 0.439 & 0.443 & 0.444 & 0.368 & 0.399 & 0.407 & 0.458 & 0.463 & 0.465 & 0.346 & 0.419 & 0.429 \\
\hline
\end{tabular}

Notes: Parameters setting: $\gamma=5, \beta=0.95$, collateralized share of income is 0.1 . The simulation moments are generated by 10,000 draws from an economy with 3,000 agents The IID Economy reports results for the Benchmark calibration of idiosyncratic shocks and i.i.d. calibration of aggregate shocks. The non-IID Economy reports results for the STY calibration of idiosyncratic shocks and MP calibration of aggregate shocks. Reports the moments of asset prices for the HTT (Heterogeneous Trading Technology) economy. The ' $1 \mathrm{x}$ ' case fixes the equity holdings of all passive traders at $5.6 \%$. The ' $2 \mathrm{x}$ ' case fixes the equity holdings of all passive traders at $11.2 \%$ 
Figure 1: Conditional Risk Premium and Market Price of Risk
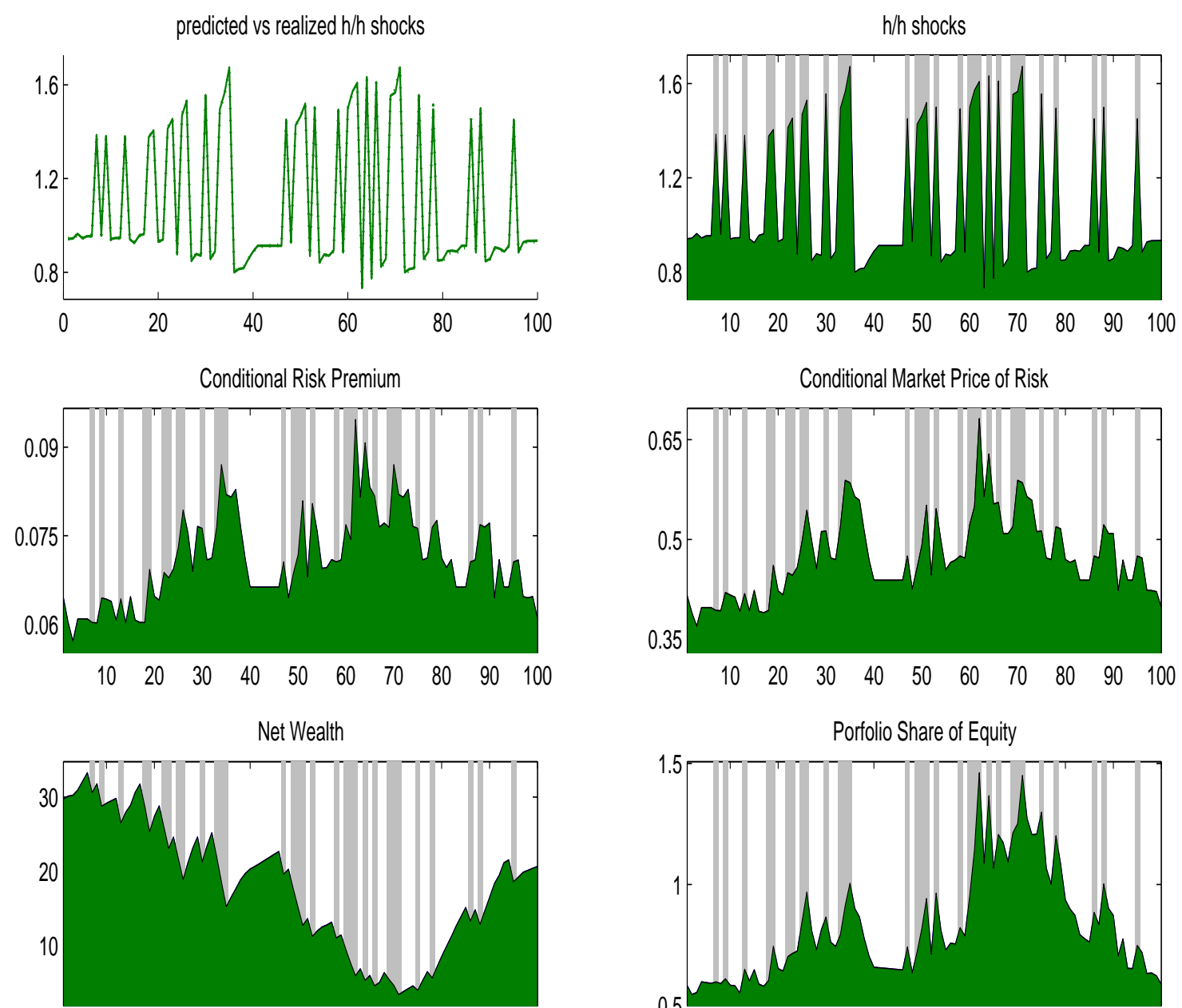

$\begin{array}{llllllllll}10 & 20 & 30 & 40 & 50 & 60 & 70 & 80 & 90 & 100\end{array}$

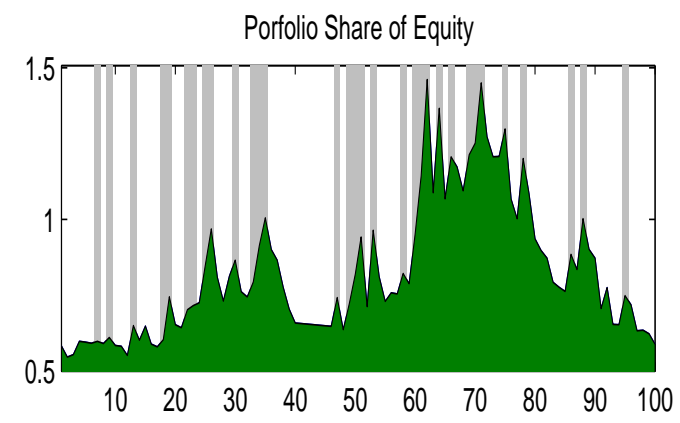

Notes: Market Segmentation Case (1): $10 \%$ in active, $20 \%$ buy-and-hold and $70 \%$ non-participants. Parameters setting: $\gamma=5$, $\beta=0.95$, collateralized share of income is 0.1. Plot of 100 draws from an economy with 3,000 agents. Benchmark calibration of idiosyncratic shocks and IID calibration of idiosyncratic shocks. The shaded are indicates low aggregate consumption growth states. 